\title{
A Comparative Elastohydrostatic Analysis of CFV- and Capillary-Compensated Multirecess Hydrostatic/Hybrid Journal Bearing Operating with Micropolar Lubricant
}

\author{
Suresh Verma, ${ }^{1}$ Vijay Kumar, ${ }^{2}$ and K. D. Gupta ${ }^{1}$ \\ ${ }^{1}$ Department of Mechanical Engineering, DCR University of Science and Technology, Murthal, Sonepat, 131039 Haryana, India \\ ${ }^{2}$ Gian Jyoti Group of Institutions, Benur, Shambu Kalan, Patiala 140417, Punjab, India \\ Correspondence should be addressed to Suresh Verma; sureshc30@yahoo.co.in
}

Received 10 January 2013; Accepted 29 January 2013

Academic Editors: J. Awrejcewicz and G. R. Fenske

Copyright (C) 2013 Suresh Verma et al. This is an open access article distributed under the Creative Commons Attribution License, which permits unrestricted use, distribution, and reproduction in any medium, provided the original work is properly cited.

A comparative study on the performance characteristics of the flexible multirecess hydrostatic journal bearing system with constant flow valve and capillary restrictors has been presented considering the effect of micropolar parameters. The modified Reynolds equation for the flow of micropolar lubricant through the bearing has been solved using finite element method, and the resulting elastic deformation in the bearing shell has been determined iteratively. The results indicate that the micropolar parameters of the lubricant affect the performance of the flexible multirecess hydrostatic journal bearing system quite significantly.

\section{Introduction}

In hydrostatic lubrication, the lubricant is pushed between the surfaces by means of an external pressurization system. The main advantages of hydrostatic lubrication are a very low friction and negligible wear, and the only drawback is a certain complexity of lubricant supply system. At present, hydrostatic lubrication is used in the entire field of mechanical engineering, from large machines, where speed is in general low, to small high-velocity machinery. Due to the absence of stick-slips and to the high degree of stiffness and damping of the pressurized fluid film, hydrostatic lubrication is particularly suitable for machines like machine tools, where medium or high precision is required to move great weights for large boring, milling, and grinding machines and numerical control machine tools, which require very accurate positioning and freedom from vibration, and telescopes and big radar antennas, which must move slowly and accurately.

In multirecess hydrostatic lubrication, the supply system must allow the different pressures to occur in the recesses. In practice, this may be accomplished either by using a separate pump to feed each recess directly, this is commonly referred to as the constant flow supply system, or by using a common source of pressurized lubricant, which is carried to each recess through compensating devices called restrictors; since the pressure is generally held constant, upstream from the restrictors (compensating devices), this is commonly referred to as the constant pressure supply systems [1]. The commonly used restrictor includes constant flow valve, capillary, orifice, and diaphragm or membrane.

It has been realized that the hydrostatic journal bearing system undergoes elastic deformation when operating under heavy loads. The bearing deformations are generally of the order of the magnitude of fluid-film thickness, and thus, the fluid-film profile is modified, and the performance of a bearing system is changed. Therefore, the studies carried out with rigid bush assumptions may not be appropriate for an accurate prediction of the performance of the bearing system.

For the Newtonian lubricant, Sinhasan et al. analytically studied the effect of bearing shell elasticity in hydrostatic journal bearing using capillary [2], constant flow valve [3], and orifice flow restrictors [4]. They presented that with the Newtonian lubricant for heavily loaded journal bearings, the deformation due to elasticity of bearing shell is comparable in magnitude with fluid-film thickness. This deformation alters the lubricant-film profile and consequently the behaviour of a journal bearing system. They concluded that the static and dynamic characteristics of bearing for a given load decrease 
as bearing flexibility increases. Their study suggested that to establish an optimum design of compensated hydrostatic journal bearing to support a particular external load, a judicious selection of restrictor design parameter, bearing shell deformation coefficient and bearing geometry, is essential. In their extended work, Sharma et al. [5] have studied the performance characteristics of flexible hydrostatic/hybrid multirecess journal bearing system operating with Newtonian lubricant and using membrane type variable flow restrictor as a compensating element. It has been concluded that a careful selection of flexibility of bearing shell is required to obtain the improved stability margin of the hydrostatic journal bearing system.

Sharma et al. [6] compared the performance characteristics of slot-entry journal bearings with that of similar holeentry-compensated journal bearings using capillary, orifice, and constant flow valve restrictors for the same bearing geometric and operating parameters. The comparative study indicates that asymmetric slot-entry journal bearings provide an improved stability threshold speed margin compared with asymmetric hole-entry journal bearings compensated by capillary, orifice, and constant flow valve restrictors.

Furthermore, while designing the hydrostatic journal bearing, generally the assumption is that the lubricant behaves as a Newtonian fluid. Nowadays, most of the modern lubricants in practice use polymeric additives to enhance their performance. The behavior of polymer-added lubricant is no longer Newtonian. In view of the inadequacies of the classical Newtonian theory, lubrication theory for micropolar fluids is applied to solve the lubrication problems of such fluids. Micropolar fluids are fluids with microstructure. They represent fluids consisting of rigid, randomly oriented particles suspended in a viscous medium, where the deformation of fluid particles is ignored.

The steady-state analysis using micropolar lubricants for infinitely long journal bearing studied by Prakash and Sinha [7] revealed that such fluids increase the effective viscosity, especially in thin films, which supported the experimental evidence also. The squeeze-film flow effects in micropolar lubrication were also studied by Prakash and Sinha [8] for the journal bearings under a cyclic sinusoidal load with no journal rotation. Later on, Singh et al. [9] presented the threedimensional Reynolds equation using micropolar lubrication theory.

Khonsari and Brewe [10] observed the improvements in the performance of the finite journal bearings and attributed it to the characteristic length and coupling number of micropolar fluids. Further, Das et al. [11] have presented the dynamic characteristics of hydrodynamic journal bearings lubricated with micropolar fluids. They obtained the dynamic characteristics in terms of the components of stiffness and damping coefficients and critical mass parameter and whirl with respect to the micropolar property for varying eccentricity ratios. They concluded that the micropolar fluid exhibits better stability in comparison with the Newtonian fluid. In their extended work, Das et al. [12] presented the performance of misaligned hydrodynamic journal bearings lubricated with micropolar fluids. Wang and Zhu [13] have studied the lubricating effectiveness of micropolar fluids in a dynamically loaded hydrodynamic journal bearing. A numerical study of the non-Newtonian behavior for a finite journal bearing lubricated with micropolar fluids has been undertaken by Wang and Zhu [14] considering both thermal and cavitation effects. They derived the modified Reynolds equation and energy equation based on Eringen's micropolar fluid theory and investigated the effects of the size of material characteristic length and the coupling number on the thermohydrodynamic performance of a journal bearing.

The micropolar theory of lubrication applied to hydrodynamic bearings has been categorically reviewed by the authors in [15]. In this, the influence of micropolar parameters, that is, characteristics length and the coupling number, on the performance of a four-pocket hydrostatic journal bearing compensated through a constant flow valve has been presented. But in that analysis, the bearing shell flexibility has not been taken into account. A study of hole-entry hybrid journal bearing system capillary compensated and operating with micropolar lubricant is presented in [16], and it has been concluded that there exists an optimum value of restrictor design parameter corresponding to micropolar lubricant at which the stiffness coefficient and stability parameters are maximum.

Nicodemus and Sharma [17] studied the influence of wear on the performance of capillary-compensated fourpocket hydrostatic journal bearing operating with micropolar lubricant for two different loading arrangements. Further, Nicodemus and Sharma [18] presented the analytical study of four-pocket-orifice-compensated hydrostatic/hybrid journal bearing system of various geometric shapes of recess operating with micropolar lubricant. They concluded that the influence of micropolar effect of the lubricant on bearing performance is predominantly affected by the geometric shape of recess and restrictor design parameter. Recently, Verma et al. [19] have theoretically studied the performance of capillary-compensated multirecessed hydrostatic journal bearings operating with micropolar lubricant, and performance has been compared with the Newtonian lubricant. Garg et al. [20] investigated the effect of viscosity variation due to temperature rise and the non-Newtonian behavior of the lubricant on the performance of hole-entry and slot-entry hybrid journal bearings system and indicated that bearing performance, can be improved by selecting a particular bearing configuration in conjunction with a suitable compensating device. Recently, Khatak and Garg [21] presented a critically analysed review article on the influence of micropolar lubricant on the bearings performance and Nicodemus and Sharma [22] analytically studied the effect of wear on the performance of a membrane-compensated hybrid journal bearing system under micropolar lubrication. Verma et al. [23] presented the analytical study of the effect of the bearing shell flexibility on the performance of constant-flowvalve-compensated multirecess hydrostatic journal bearing system operating with micropolar lubricant. Very recently, Sharma and Rajput [24] presented the theoretical study which describes the effect of geometric imperfections of journal on the performance of micropolar-lubricated four-pocket hybrid journal bearing. To the best knowledge of the authors so far, no comparative study is yet available in the literature 
that considers the influence of micropolar parameters and bearing shell flexibility on the performance of constant flow valve and the capillary-compensated hydrostatic journal bearings. The present work deals with this comparison study, wherein the simultaneous solution of the modified Reynolds equation for micropolar lubricant and elasticity equations has been obtained to compare the performance of fourpocket flexible hydrostatic journal bearing compensated with constant flow valve and capillary restrictor.

\section{Analysis}

Figure 1 shows geometric configuration of a compensated four-pocket hydrostatic journal bearing.

2.1. The Modified Reynolds Equation for Micropolar Lubricant. The flow of micropolar lubricant in the convergent area of the journal bearing is governed by the modified Reynolds equation. With the usual assumptions of the lubrication film, the modified Reynolds equation is given as [9]

$$
\frac{\partial}{\partial x}\left\{\frac{h^{3} \Phi}{12 \mu} \frac{\partial p}{\partial x}\right\}+\frac{\partial}{\partial y}\left\{\frac{h^{3} \Phi}{12 \mu} \frac{\partial p}{\partial y}\right\}=\frac{\omega_{J} R_{J}}{2} \frac{\partial h}{\partial x}+\frac{\partial h}{\partial t},
$$

where

$$
\begin{gathered}
\Phi=1+\frac{12 l^{2}}{h^{2}}-\frac{6 N l}{h} \operatorname{coth}\left(\frac{N h}{2 l}\right), \\
N=\left(\frac{\kappa}{2 \mu+\kappa}\right)^{1 / 2} ; \quad l=\left(\frac{\gamma}{4 \mu}\right)^{1 / 2} .
\end{gathered}
$$

Here $\mu$ is the viscosity coefficient of the Newtonian fluid, $\kappa$ is the spin viscosity, $\gamma$ is the material coefficient, $h$ is the film thickness, and $p$ is the micropolar fluid-film pressure. $N$ and $l$ are two parameters distinguishing a micropolar lubricant from Newtonian lubricant. $N$ is a dimensionless parameter called the coupling number which couples the linear and angular momentum equations arising from the microrotational effects of the suspended particles in the lubricant. $l$ represents the interaction between the micropolar lubricant and the film gap and is termed as the characteristic length of the micropolar lubricant.

Equation (1) in its nondimensional form can be given as

$$
\frac{\partial}{\partial \alpha}\left\{\frac{\bar{h}^{3} \Phi}{12 \bar{\mu}} \frac{\partial \bar{p}}{\partial \alpha}\right\}+\frac{\partial}{\partial \beta}\left\{\frac{\bar{h}^{3} \Phi}{12 \bar{\mu}} \frac{\partial \bar{p}}{\partial \beta}\right\}=\frac{\Omega}{2} \frac{\partial \bar{h}}{\partial \alpha}+\frac{\partial \bar{h}}{\partial \bar{t}},
$$

where

$$
\Phi=1+\frac{12}{\bar{h}^{2} l_{m}^{2}}-\frac{6 N}{\bar{h} l_{m}} \operatorname{coth}\left(\frac{N \bar{h} l_{m}}{2}\right) .
$$

Using the finite element method based on Galerkin's technique and (3), the system equation for the discretized flow field is derived, and in matrix form it is given as

$$
\bar{F}\{\bar{p}\}=\{\bar{Q}\}+\Omega\left\{\bar{R}_{H}\right\}+\overline{\dot{X}}_{J}\left\{\bar{R}_{x j}\right\}+\overline{\dot{Z}}_{J}\left\{\bar{R}_{z j}\right\} .
$$

A dot over terms represents first derivative of the respective terms with respect to time. In the Expanded form the equation (5) is

$$
\begin{aligned}
& {\left[\begin{array}{cccccc}
\bar{F}_{11} & \bar{F}_{12} & \cdots & \bar{F}_{1 j} & \cdots & \bar{F}_{1 n} \\
\vdots & \vdots & \vdots & \vdots & \vdots & \vdots \\
\bar{F}_{i 1} & \bar{F}_{i 2} & \cdots & \bar{F}_{i j} & \cdots & \bar{F}_{i n} \\
\vdots & \vdots & \vdots & \vdots & \vdots & \vdots \\
\bar{F}_{j 1} & \bar{F}_{j 2} & \cdots & \bar{F}_{j j} & \cdots & \bar{F}_{j n} \\
\vdots & \vdots & \vdots & \vdots & \vdots & \vdots \\
\bar{F}_{n 1} & \bar{F}_{n 2} & \cdots & \bar{F}_{n j} & \cdots & \bar{F}_{n n}
\end{array}\right]\left\{\begin{array}{c}
\bar{p}_{1} \\
\vdots \\
\bar{p}_{i} \\
\vdots \\
\bar{p}_{j} \\
\vdots \\
\bar{p}_{n}
\end{array}\right\}} \\
& =\left\{\begin{array}{c}
\bar{Q}_{1} \\
\vdots \\
\bar{Q}_{i} \\
\vdots \\
\bar{Q}_{j} \\
\vdots \\
\bar{Q}_{n}
\end{array}\right\}+\Omega \\
&
\end{aligned}
$$

Each term of respective matrix/vector is computed using the following expressions:

$$
\bar{F}_{i j}^{e}=\iint_{\vec{A}^{e}}\left\{\frac{\bar{h}^{3}}{12 \bar{\mu}}\left(\Phi \frac{\partial N_{i}}{\partial \alpha} \frac{\partial N_{j}}{\partial \alpha}+\Phi \frac{\partial N_{i}}{\partial \beta} \frac{\partial N_{j}}{\partial \beta}\right)\right\} d \alpha d \beta,
$$

$$
\begin{aligned}
\left\{\bar{Q}_{i}\right\}^{e}= & \int_{\Gamma^{e}}\left\{\left(\frac{\bar{h}^{3}}{12 \bar{\mu}}\left(\Phi \frac{\partial \bar{p}}{\partial \alpha}\right)-\frac{\bar{\Omega}}{2} \bar{h}\right) l_{1}+\frac{\bar{h}^{3}}{12 \bar{\mu}}\left(\Phi \frac{\partial \bar{p}}{\partial \beta}\right) l_{2}\right\}, \\
& \times N_{i} d \bar{\Gamma}^{e} \\
\bar{R}_{H i}^{e}= & \iint_{\bar{A}^{e}} \frac{\bar{h}}{2} \frac{\partial N_{i}}{\partial \alpha} d \alpha d \beta, \\
\bar{R}_{x j i}^{e}= & \iint_{\bar{A}^{e}} \cos \alpha N_{i} d \alpha d \beta, \\
\bar{R}_{z j i}^{e}= & \iint_{\bar{A}_{e}} \sin \alpha N_{i} d \alpha d \beta,
\end{aligned}
$$

where $l_{1}$ and $l_{2}$ are directions cosines, $i, j=1,2, \ldots, n_{l}^{e}$ (number of nodes per element) are local node numbers, and $\bar{A}$ and $\Gamma$ are solution domains.

2.2. Fluid-Film Thickness. The journal bearing is required to maintain an appropriate minimum fluid-film thickness to minimize the chances of metal to metal contact under the operating load. For a rigid journal bearing system, the fluidfilm thickness expression is given as

$$
\bar{h}=\bar{h}_{o}+\Delta \bar{h},
$$




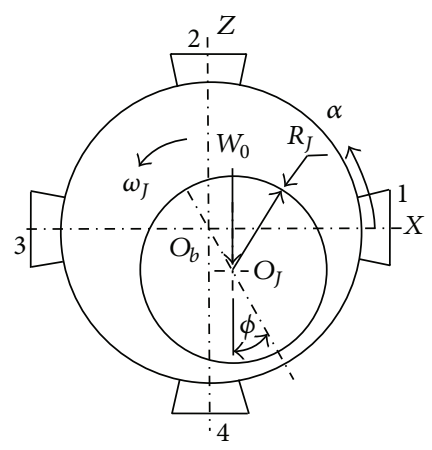

(a)

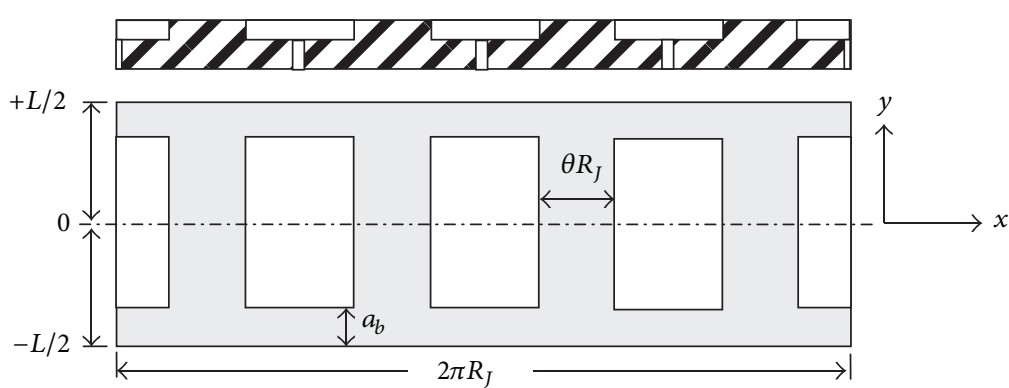

(b)

FIgURE 1: (a) Four-pocket hydrostatic bearing coordinate system. (b) Bearing geometry.

where $\Delta \bar{h}$ is the perturbation due to dynamic condition on the fluid-film thickness and $\bar{h}_{o}$ is the fluid-film thickness when the journal center is at the static equilibrium position and is given as

$$
\bar{h}_{o}=1-\bar{X}_{J} \cos \alpha-\bar{Z}_{J} \sin \alpha .
$$

Now, for a flexible bearing, the fluid-film thickness gets modified due to elastic deformation, and the modified film thickness is given as

$$
\bar{h}=\bar{h}_{o}+\Delta \bar{h}+\bar{\delta}_{r}
$$

where $\bar{\delta}_{r}$ represents nondimensional radial elastic deformation due to the fluid-film pressure.

2.3. Restrictor Flow Equation. For a compensated journal bearing system, the continuity of flow between restrictor and bearing is required to be maintained. The flow through the restrictor is therefore taken as a constraint in the solution domain. The constant flow valve restrictor should be able to supply a fixed quantity of lubricant through it; hence, the flow $\bar{Q}_{R}$ of lubricant through it is expressed as

$$
\bar{Q}_{R}=\text { constant }=\bar{Q}_{c} .
$$

Here, $\bar{Q}_{R}$ and $\bar{Q}_{c}$ represent the restrictor flow and pocket flow, respectively.

In a capillary-compensated hydrostatic journal bearing system, continuity of lubricant flow rate between the restrictor and the bearing is maintained. The lubricant flow rate $\bar{Q}_{R}$ through capillary restrictor neglecting gravitational force in nondimensional form is given as [2]

$$
\bar{Q}_{R}=\bar{C}_{s 2}\left(1-\bar{p}_{c}\right) \text {. }
$$

2.4. Fluid-Film Stiffness and Damping Coefficients. The fluidfilm stiffness coefficients are defined as

$$
\bar{S}_{i j}=-\frac{\partial \bar{F}_{i}}{\partial \bar{q}_{J}}, \quad(i=x, z),
$$

where " $i$ " represents the direction of force; $\bar{q}_{J}$ is the direction of journal center displacement $\left(\bar{q}_{J}=\left(\bar{X}_{J}, \bar{Z}_{J}\right)\right)$.

Stiffness coefficient in matrix form will be

$$
\left[\begin{array}{ll}
\bar{S}_{x x} & \bar{S}_{x z} \\
\bar{S}_{z x} & \bar{S}_{z z}
\end{array}\right]=-\left[\begin{array}{ll}
\frac{\partial \bar{F}_{x}}{\partial \bar{X}_{J}} & \frac{\partial \bar{F}_{x}}{\partial \bar{Z}_{J}} \\
\frac{\partial \bar{F}_{z}}{\partial \bar{X}_{J}} & \frac{\partial \bar{F}_{z}}{\partial \bar{Z}_{J}}
\end{array}\right] .
$$

For the computation of stiffness coefficients $\left(\bar{S}_{i j}(i, j=\right.$ $\left.\bar{X}_{J}, \bar{Z}_{J}\right)$ ) of a journal bearing system, the nodal pressure derivatives at steady-state conditions are to be calculated by differentiating the system equation (5) with respect to journal displacement $\left(\bar{X}_{J}, \bar{Z}_{J}\right)$. The element of the RHS matrices in the differentiation of the system equation (5) is computed, and the values of pressure derivatives $\left(\partial \bar{p}_{0} / \partial \bar{X}_{J}, \partial \bar{p}_{0} / \partial \bar{Z}_{J}\right)$ can be obtained. Using the values of pressure derivatives, the components of the RHS matrix of (13) can be computed.

The fluid-film damping coefficients are defined as

$$
\bar{C}_{i j}=-\frac{\partial \bar{F}_{i}}{\partial \overline{\dot{q}}_{J}}, \quad(i=x, z),
$$

where $\overline{\dot{q}}_{J}$ represents the velocity component of journal center $\left(\overline{\dot{q}}_{J}=\left(\overline{\dot{X}}_{J}, \overline{\dot{Z}}_{J}\right)\right)$.

Damping coefficients in matrix form are

$$
\left[\begin{array}{ll}
\bar{C}_{x x} & \bar{C}_{x z} \\
\bar{C}_{z x} & \bar{C}_{z z}
\end{array}\right]=-\left[\begin{array}{ll}
\frac{\partial \bar{F}_{x}}{\partial \dot{X}_{J}} & \frac{\partial \bar{F}_{x}}{\partial \dot{\bar{Z}}_{J}} \\
\frac{\partial \bar{F}_{z}}{\partial \bar{X}_{J}} & \frac{\partial \bar{F}_{z}}{\partial \dot{\bar{Z}}_{J}}
\end{array}\right] .
$$

For the computation of damping coefficients $\left(\bar{C}_{i j}(i, j=\right.$ $\left.\left.\overline{\dot{X}}_{J}, \overline{\dot{Z}}_{J}\right)\right)$, the nodal pressure derivatives $\left(\partial \bar{p}_{0} / \partial \overline{\dot{X}}_{J}, \partial \bar{p}_{0} / \partial \overline{\dot{Z}}_{J}\right)$ are required. These may be obtained by differentiating the global system equation (5) with respect to $\left(\overline{\dot{q}}_{J}=\overline{\dot{X}}_{J}, \overline{\dot{Z}}_{J}\right)$. 
2.4.1. Stability Parameters. For a very small disturbance from the equilibrium position, the hydrodynamic forces in the journal can be regarded as linear functions of the displacements and the velocity vectors. The equation of the disturbed motion of the journal can be written by equating the inertia force to the stiffness and the damping forces. The linearized equation of motion of the journal in the nondimensional form is given by

$$
\left[\bar{M}_{J}\right]\left\{\bar{X}_{J}\right\}+[\bar{C}]\left\{\bar{X}_{J}\right\}+[\bar{S}]\left\{\bar{X}_{J}\right\}=0
$$

Using Routh's criteria, the stability margin of the journal bearing system, in terms of critical mass $\bar{M}_{c}$, is obtained. The system is stable when $\bar{M}_{J}<\bar{M}_{c}$. The nondimensional critical mass $\bar{M}_{c}$ of the journal is expressed as

$$
\begin{aligned}
& \bar{M}_{c}=\frac{\bar{G}_{1}}{\bar{G}_{2}-\bar{G}_{3}}, \quad \bar{G}_{1}=\left[\bar{C}_{x x} \bar{C}_{z z}-\bar{C}_{z x} \bar{C}_{x z}\right], \\
& \bar{G}_{2}=\frac{\left[\bar{S}_{x x} \bar{S}_{z z}-\bar{S}_{z x} \bar{S}_{x z}\right]\left[\bar{C}_{x x}+\bar{C}_{z z}\right]}{\left[\bar{S}_{x x} \bar{C}_{z z}+\bar{S}_{z z} \bar{C}_{x x}-\bar{S}_{x z} \bar{C}_{z x}-\bar{S}_{z x} \bar{C}_{x z}\right]}, \\
& \bar{G}_{3}=\frac{\left[\bar{S}_{x x} \bar{C}_{x x}+\bar{S}_{x z} \bar{C}_{x z}+\bar{S}_{z x} \bar{C}_{z x}+\bar{S}_{z z} \bar{C}_{z z}\right]}{\left[\bar{C}_{x x}+\bar{C}_{z z}\right]} .
\end{aligned}
$$

Threshold speed, that is, the speed of journal at the threshold of instability, can be obtained using the relation given as

$$
\bar{\omega}_{\mathrm{th}}=\left[\frac{\bar{M}_{c}}{\bar{F}_{o}}\right]^{1 / 2}
$$

where $\bar{F}_{o}$ is the resultant fluid-film force or reaction $(\partial \bar{h} / \partial \bar{t}=$ $0)$.

2.5. Elastic Continuum. In general, bearing shell or bush is considered to be cylindrical structure of finite length enclosed in a rigid housing. Using the linear elasticity equation, virtual work principle, and finite element formulation, the system equation governing deformation in an elastic continuum is derived. At a point in elastic continuum, the displacements in the circumferential $\left(\delta_{x}\right)$, axial $\left(\delta_{y}\right)$, and radial $\left(\delta_{z}\right)$ directions are defined. The radial component at fluid film and shell interference is needed for the computation of fluid-film thickness. Generally, in practical conditions, the rigidity of the journal is more as compared to that of shell, and hence, deformation in the journal due to fluid-film pressure has been neglected in the present study.

By using the nondimensional scheme given as

$$
\begin{gathered}
\alpha=\left(\frac{x}{R_{J}}\right), \quad \beta=\left(\frac{y}{R_{J}}\right), \quad \bar{r}=\left(\frac{r}{R_{J}}\right), \\
{[\bar{D}]=\left(\frac{[D]}{E_{b}}\right), \quad\{\bar{\delta}\}=\left(\frac{\{\delta\}}{c}\right),}
\end{gathered}
$$

the discretized elastic continuum system equation is as follows [16]:

$$
[\bar{K}]\{\bar{\delta}\}=\bar{C}_{d}\left\{\bar{F}_{\Gamma}\right\}
$$

where $[\bar{K}]=$ system stiffness matrix, $\{\bar{\delta}\}=$ system nodal displacement vector, $\left\{\bar{F}_{\Gamma}\right\}=$ system traction force vector, and $\bar{C}_{d}=$ elastic deformation coefficient $\left(=\left(p_{s} t_{h}\right) /\left(E_{b} c\right)\right)$.

\section{Boundary Conditions}

The relevant boundary conditions are as follow.

(1) Nodes situated on the external boundary of the bearing have zero pressure $\left.\bar{p}\right|_{\beta= \pm \lambda}=0.0$.

(2) All the nodes situated on a pocket have equal pressure.

(3) Flow of lubricant through the restrictor $\left(\bar{Q}_{R}\right)$ is equal to the bearing input flow.

(4) At the trailing edge of the positive region $\bar{p}=$ $(\partial \bar{p} / \partial \alpha)=0$.

(5) The displacement of the nodes on shell-housing interface is zero $(\bar{\delta}=0)$.

The global system equations from the governing Equations (5), (8), (10a), (11), and (20) are obtained by employing Galerkin's orthogonality criterion and then solved after applying appropriate boundary conditions. The entire lubricant flow field is discretized using four-noded quadrilateral isoparametric elements. The two-dimensional grid is used for the solution of the modified Reynolds equation along the two directions (i.e., circumferential and axial). The displacement field is discretized using 8 -noded isoparametric hexahedral elements.

\section{Solution Scheme}

The modified Reynolds equation governing the flow of micropolar lubricant in the clearance space of a four-pocket hydrostatic journal bearing system has been solved by using finite element method together with required boundary conditions. The solution of a constant flow valve or capillarycompensated hydrostatic journal bearing system problem needs iterative solution scheme for solving (5). Under steadystate condition $\left(\overline{\dot{X}}_{J}, \overline{\dot{Z}}_{J}=0\right)$ assuming the rigid bearing shell $\left(\bar{C}_{d}=0\right)$, the lubricant flow field system equation (5) is solved for a specified journal center position $\left(\bar{X}_{J}, \bar{Z}_{J}\right)$ after adjustment for flow through constant flow valve restrictor equations (10a) and (11) and modified for the boundary conditions. But if the solution is to be obtained for a specified vertical load, one additional iterative loop is needed to establish the equilibrium journal center position using the following equations:

$$
\bar{F}_{X}=0, \quad \bar{F}_{Z}-\bar{W}_{0}=0 .
$$

Under a given bearing geometric parameters and for a given external vertical load, journal center position $\left(\bar{X}_{J}, \bar{Z}_{J}\right)$ 
is unique. For a given external load, tentative values of the journal center coordinates are fed as input. The corrections $\left(\Delta \bar{X}_{J}, \Delta \bar{Z}_{J}\right)$ on the assumed journal center coordinates $\left(\bar{X}_{J}, \bar{Z}_{J}\right)$ are computed using the following algorithm.

The fluid-film reaction components $\bar{F}_{x}, \bar{F}_{z}$ are expressed by Taylor's series about $i$ th journal center position. Assuming that the alteration in the journal center position is quite small and retaining terms only up to first order in Taylor's series expansion, the corrections $\left(\Delta \bar{X}_{J}, \Delta \bar{Z}_{J}\right)$ on the coordinates are obtained as

$$
\begin{aligned}
& \left.\Delta \bar{X}_{J}\right|_{i}=-\frac{1}{D_{J}}\left[\left.\frac{\partial \bar{F}_{z}}{\partial \bar{Z}_{J}}\right|_{i} \quad-\left.\frac{\partial \bar{F}_{x}}{\partial \bar{Z}_{J}}\right|_{i}\right]\left\{\begin{array}{c}
\left.\bar{F}_{x}\right|_{i} \\
\left.\bar{F}_{z}\right|_{i}-\bar{W}_{0}
\end{array}\right\}, \\
& \left.\Delta \bar{Z}_{J}\right|_{i}=-\frac{1}{D_{J}}\left[-\left.\left.\frac{\partial \bar{F}_{z}}{\partial \bar{X}_{J}}\right|_{i} \quad \frac{\partial \bar{F}_{x}}{\partial \bar{X}_{J}}\right|_{i}\right]\left\{\begin{array}{c}
\left.\bar{F}_{x}\right|_{i} \\
\left.\bar{F}_{z}\right|_{i}-\bar{W}_{0}
\end{array}\right\},
\end{aligned}
$$

where

$$
D_{J}=\left[\left.\left.\frac{\partial \bar{F}_{x}}{\partial \bar{X}_{J}}\right|_{i} \frac{\partial \bar{F}_{z}}{\partial \bar{Z}_{J}}\right|_{i}-\left.\left.\frac{\partial \bar{F}_{x}}{\partial \bar{Z}_{J}}\right|_{i} \frac{\partial \bar{F}_{z}}{\partial \bar{X}_{J}}\right|_{i}\right]
$$

The new journal center position coordinates $\left[\left.\bar{X}_{J}\right|_{i+1}\right.$, $\left.\left.\bar{Z}_{J}\right|_{i+1}\right]$ are expressed as

$$
\begin{aligned}
& \left.\bar{X}_{J}\right|_{i+1}=\left.\bar{X}_{J}\right|_{i}+\left.\Delta \bar{X}_{J}\right|_{i}, \\
& \left.\bar{Z}_{J}\right|_{i+1}=\left.\bar{Z}_{J}\right|_{i}+\left.\Delta \bar{Z}_{J}\right|_{i} .
\end{aligned}
$$

Iterations are continued until the following convergence criterion is satisfied:

$$
\left|\frac{\left(\left(\Delta \bar{X}_{j}^{i}\right)^{2}+\left(\Delta \bar{Z}_{j}^{i}\right)^{2}\right)^{1 / 2}}{\left(\left(\bar{X}_{j}^{i}\right)^{2}+\left(\bar{Z}_{j}^{i}\right)^{2}\right)^{1 / 2}}\right|<0.001 .
$$

Once the journal centre equilibrium position is established, the nodal displacements $(\bar{\delta})$ in the elastic domain (bearing shell) are computed using the pressure developed in the fluid film, the system equation (20), and the boundary conditions. The fluid-film thickness $(\bar{h})$ is modified using (9) and the radial displacement component $\left(\bar{\delta}_{r}\right)$ of the nodes on the fluid-film-elastic domain interface. Using the modified film thickness, the flow field system equation (5) is again solved for the steady-state case, and new nodal pressures and flows are obtained. Using these nodal pressures, nodal displacements $(\bar{\delta})$ in the elastic domain are again computed using the system equation (20). Iterations are continued till the differences in the nodal pressures of successive iterations do not come within the specified tolerance limit of $0.1 \%$. The flow chart of the iteration scheme is shown in Figure 2. After
TABLE 1: Bearing operating and geometric parameters.

\begin{tabular}{lc}
\hline Bearing aspect ratio, $\lambda=L / D$ & 1.0 \\
Concentric pressure ratio, $\beta^{*}$ & 0.5 \\
Speed parameter, $\Omega$ & $0.0 / 0.5$ \\
Number of pockets & 4 \\
Land width ratio, $\bar{a}_{b}$ & 0.14 \\
External load, $\bar{W}_{o}$ & 0.5 \\
Flexibility parameter, $\bar{C}_{d}$ & $0.0 / 0.5$ \\
Poisson's ratio, $v$ & 0.3 \\
Bearing shell thickness ratio, $\bar{t}_{h}$ & 0.1 \\
\hline
\end{tabular}

establishing the matched steady-state solution for the nodal pressures, the static and dynamic performance characteristics of the bearing system are computed.

\section{Results and Discussion}

The validity of the computer program developed is established by computing the load at different eccentricity ratios for rigid hydrodynamic bearing operating with the Newtonian and micropolar lubricants. The results obtained from the present work have been compared with the available theoretical results of Wang and Zhu [14] and found to be quite close as shown in Figure 3(a). The maximum deviation of about $8 \%$ and $7 \%$ is noted for the Newtonian and micropolar lubricant, respectively, at maximum eccentricity ratio of 0.8 . The difference in the analytical solutions may be attributed to the different computational scheme used. Further, Figures 3(b) and 3(c) show the comparison of the present results for a constant flow valve and capillary-compensated, respectively, four-pocket flexible hydrostatic journal bearing system operating with the Newtonian lubricant and for minimum fluidfilm thickness $\left(\bar{h}_{\text {min }}\right)$ with restrictor flow $\left(\bar{Q}_{c}\right)$ and restrictor design parameter $\left(\bar{C}_{S 2}\right)$ at different values of the deformation coefficient $\left(\bar{C}_{d}\right)$, with existing results of Sinhasan et al. [2, 3]. They compare very well.

The comparison between the performance characteristics of the multirecessed hydrostatic/hybrid journal bearings compensated with constant flow valve (CFV) and capillary restrictors has been presented in this section. The numerically computed results for the bearing compensated with CFV or capillary restrictors are compared having operating and geometric parameters as given in Table 1.

For the purpose of comparison of bearing performance with constant flow valve and capillary restrictors, a concentric pressure ratio $\left(\beta^{*}\right)$ of 0.5 is taken as a common parameter among these restrictors. It is to be noted that this value of $\beta^{*}$ corresponds to $\bar{Q}_{c}=0.935$ for the $\mathrm{CFV}$ and the restrictor design parameter $\bar{C}_{S 2}=0.4675$ for the capillary restrictor, respectively, in the present cases. The performance characteristics are plotted in terms of bar charts as shown in Figures 4-12 for four-pocket hydrostatic rigid $\left(\bar{C}_{d}=0.0\right)$ as well as flexible $\left(\bar{C}_{d}=0.5\right)$ bearing configurations for direct comparison. The performance characteristics are compared 


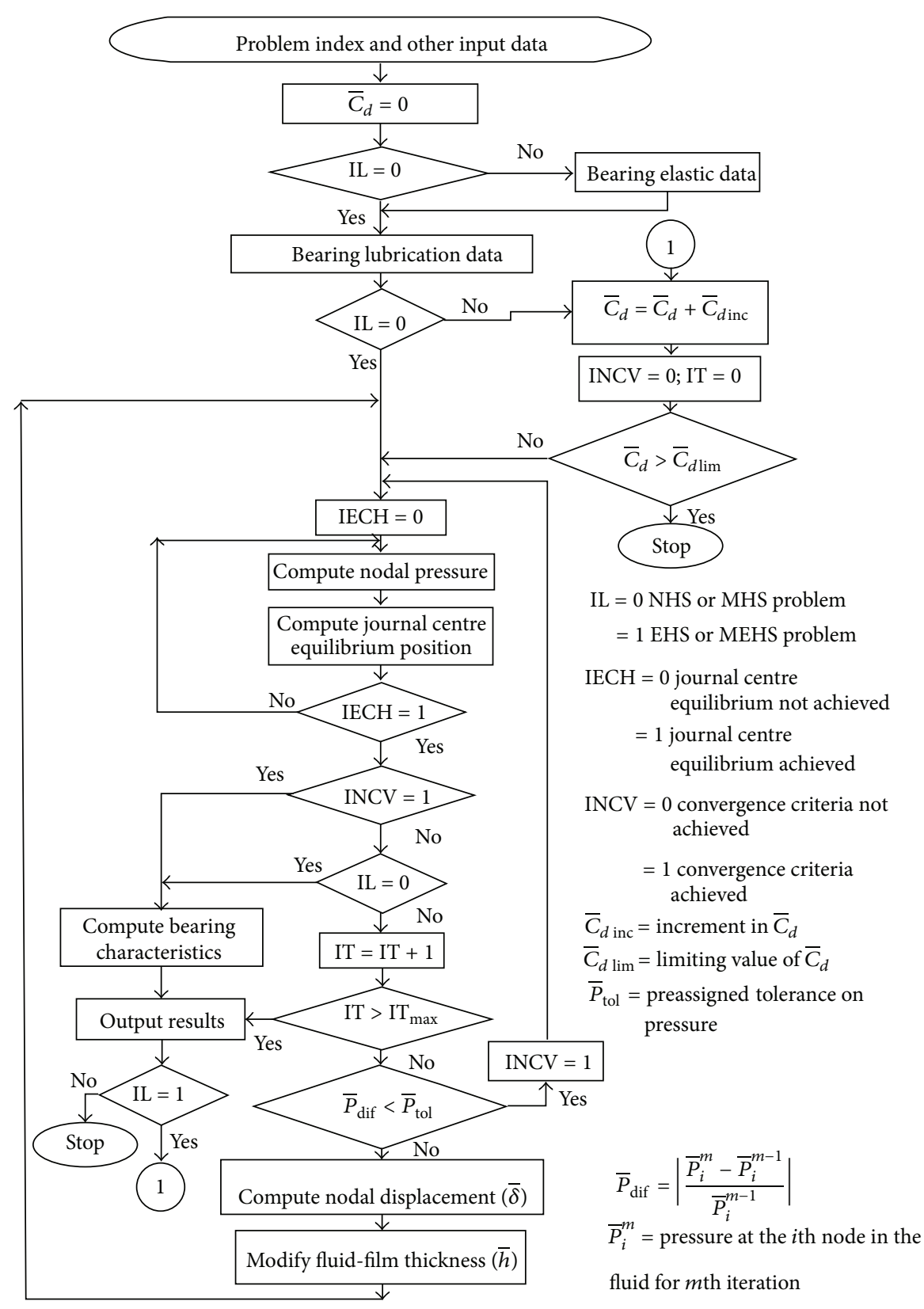

FIGURE 2: Iterative scheme of solution.

for the Newtonian and micropolar lubricants with micropolar parameters as $N^{2}=10,20$ and $l_{m}=0.5,0.9$.

\subsection{Comparison of Performance Characteristics in Hydrostatic} Mode. In this section, the comparison between the performance characteristics of the multirecessed hydrostatic/hybrid journal bearings compensated with constant flow valve $(\mathrm{CFV})$ and capillary restrictors has been presented at speed parameter $\Omega=0.0$.

It can be observed from Figure 4 that the value of $\bar{p}_{\max }$ for rigid journal bearing configuration is found more than the corresponding flexible bearing. In general, it is noted that the bearing compensated with CFV gives the maximum value of $\bar{p}_{\max }$ for all the values of the micropolar parameters $\left(N^{2}=\infty\right.$, 20,$\left.10 ; l_{m}=0.0,0.5,0.9\right)$ of the lubricant. The value of $\bar{p}_{\max }$ is seen to follow a definite pattern for rigid as well as the flexible bearing as given by

$$
\begin{aligned}
& \left(\left.\bar{p}_{\text {max }}\right|_{\text {CFV }}\right)_{\text {Rigid }}>\left(\left.\bar{p}_{\text {max }}\right|_{\text {CFV }}\right)_{\text {Flexible }}>\left(\left.\bar{p}_{\text {max }}\right|_{\text {Capillary }}\right)_{\text {Rigid }} \\
& >\left(\left.\bar{p}_{\text {max }}\right|_{\text {Capillary }}\right)_{\text {Flexible }}
\end{aligned}
$$

for the Newtonian and micropolar lubricants.

The comparison of the value of minimum fluid-film thickness $\left(\bar{h}_{\min }\right)$ of the four-pocket hydrostatic journal bearing compensated with different flow control devices is shown 


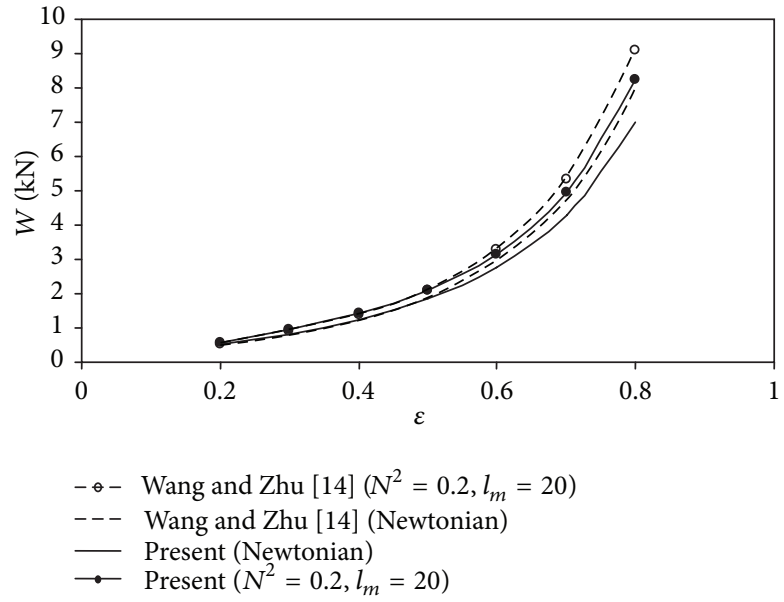

(a)

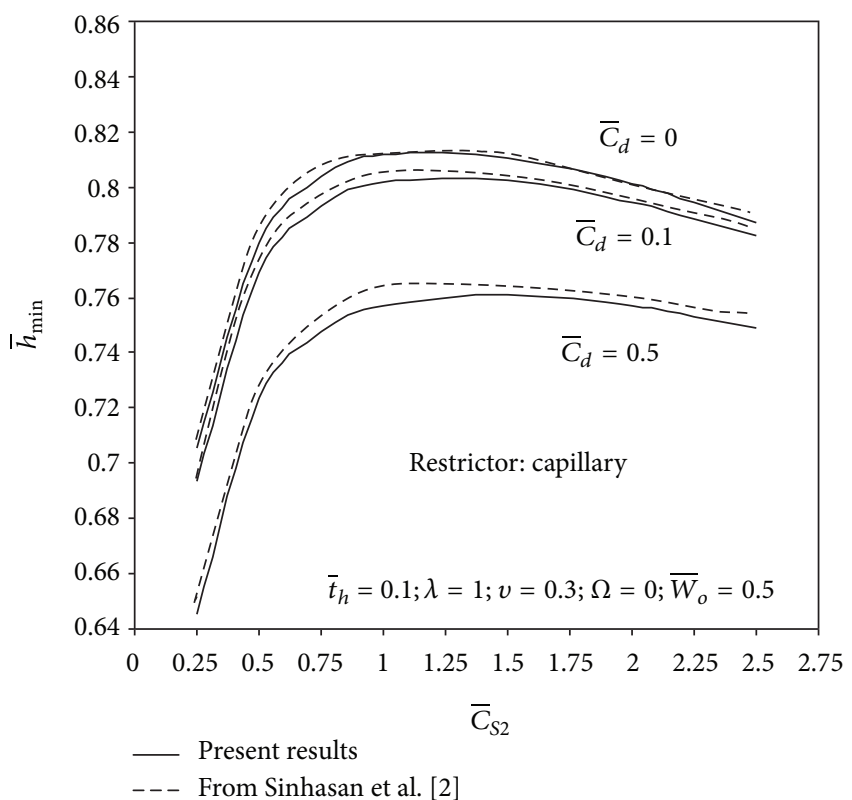

(b)

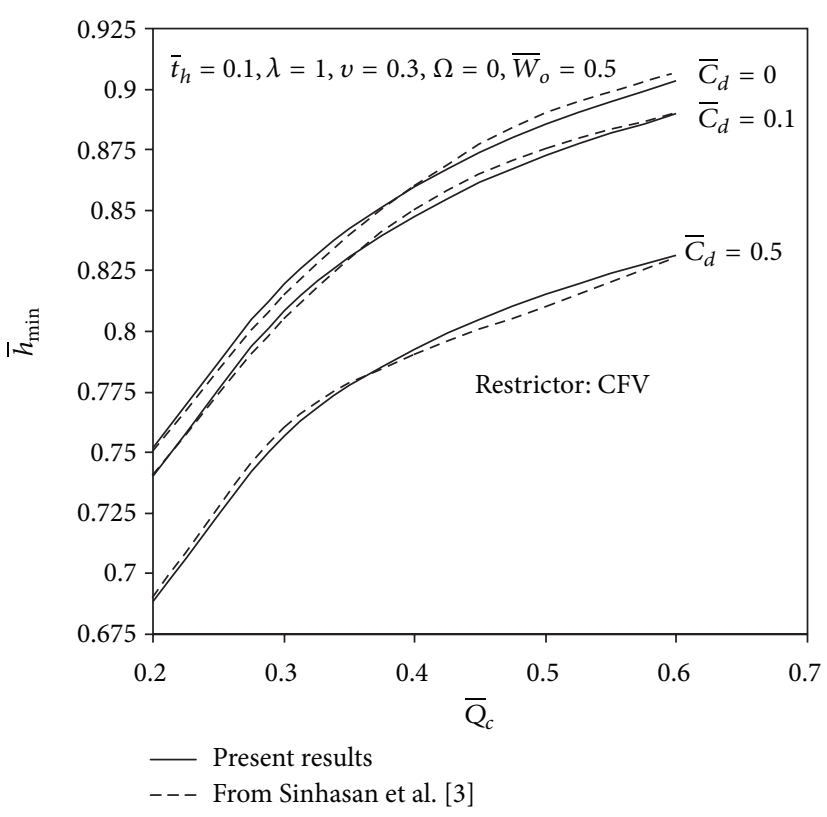

(c)

Figure 3: (a) Variation of load-carrying capacity $W(\mathrm{kN})$ with eccentricity ratio $(\varepsilon)$ for rigid hydrodynamic journal bearing. (b) Comparison of present result of flexible four-pocket bearing with Newtonian lubricant and capillary restrictor. (c) Comparison of present result of flexible four-pocket bearing with Newtonian lubricant and CFV restrictor.

in Figure 5. It is observed from Figure 5 that for rigid as well as the flexible bearing, constant flow-valve compensated bearing shows maximum value of minimum fluid-film thickness, while the capillary-compensated bearing shows the lower value of $\bar{h}_{\min }$ for the both the Newtonian and micropolar lubricants. The following general trend is observed for all the values of micropolar parameters of the lubricant:

$$
\begin{aligned}
& \left(\left.\bar{h}_{\text {min }}\right|_{\text {CFV }}\right)_{\text {Rigid }}>\left(\left.\bar{h}_{\text {min }}\right|_{\text {CFV }}\right)_{\text {Flexible }}>\left(\left.\bar{h}_{\text {min }}\right|_{\text {Capillary }}\right)_{\text {Rigid }} \\
& >\left(\left.\bar{h}_{\text {min }}\right|_{\text {Capillary }}\right)_{\text {Flexible }} .
\end{aligned}
$$

Figure 6 shows the variation of bearing flow requirement $\bar{Q}$ of the four-pocket journal bearings studied. It is clear from the figure that flow requirement of flexible bearing is found to be more as compared to rigid bearing for capillary restrictor for all the values of micropolar parameters. The following trends are observed:

$$
\begin{gathered}
\left(\left.\bar{Q}\right|_{\text {Capillary }}\right)_{\text {Flexible }}>\left(\left.\bar{Q}\right|_{\text {Capillary }}\right)_{\text {Rigid }} \\
>\left(\left(\left.\bar{Q}\right|_{\text {CFV }}\right)_{\text {Rigid }}=\left(\left.\bar{Q}\right|_{\text {CFV }}\right)_{\text {Flexible }}\right)
\end{gathered}
$$

for the Newtonian lubricant; 


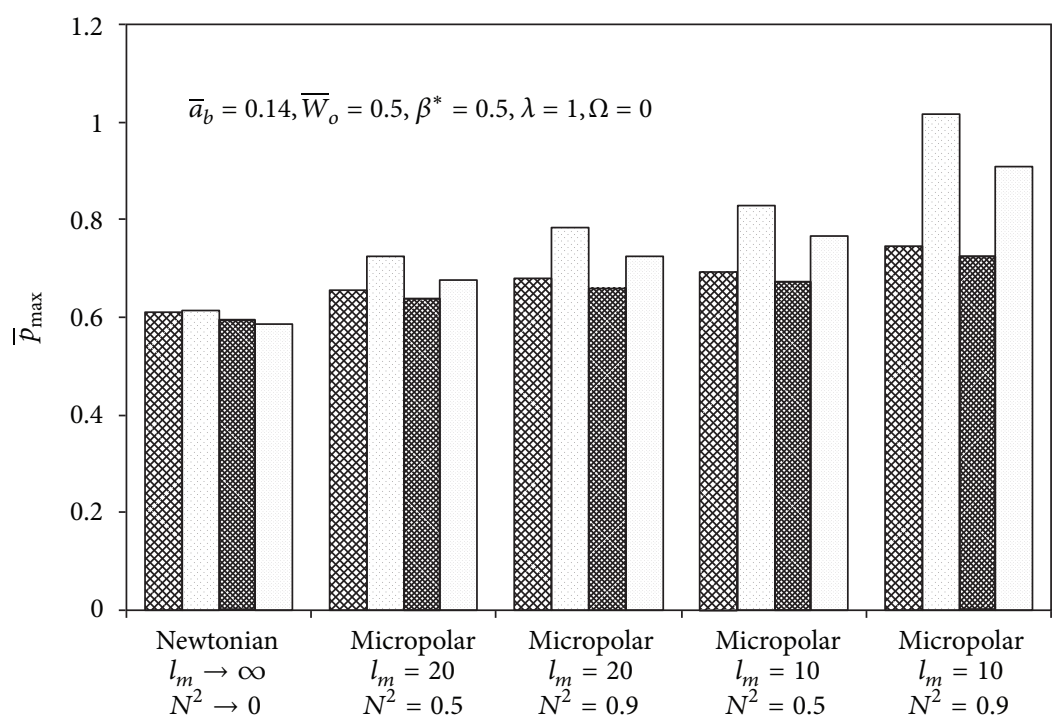
Capillary $\bar{C}_{d}=0$

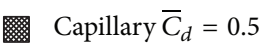
$\mathrm{CFV} \bar{C}_{d}=0$
$\square \mathrm{CFV} \bar{C}_{d}=0.5$

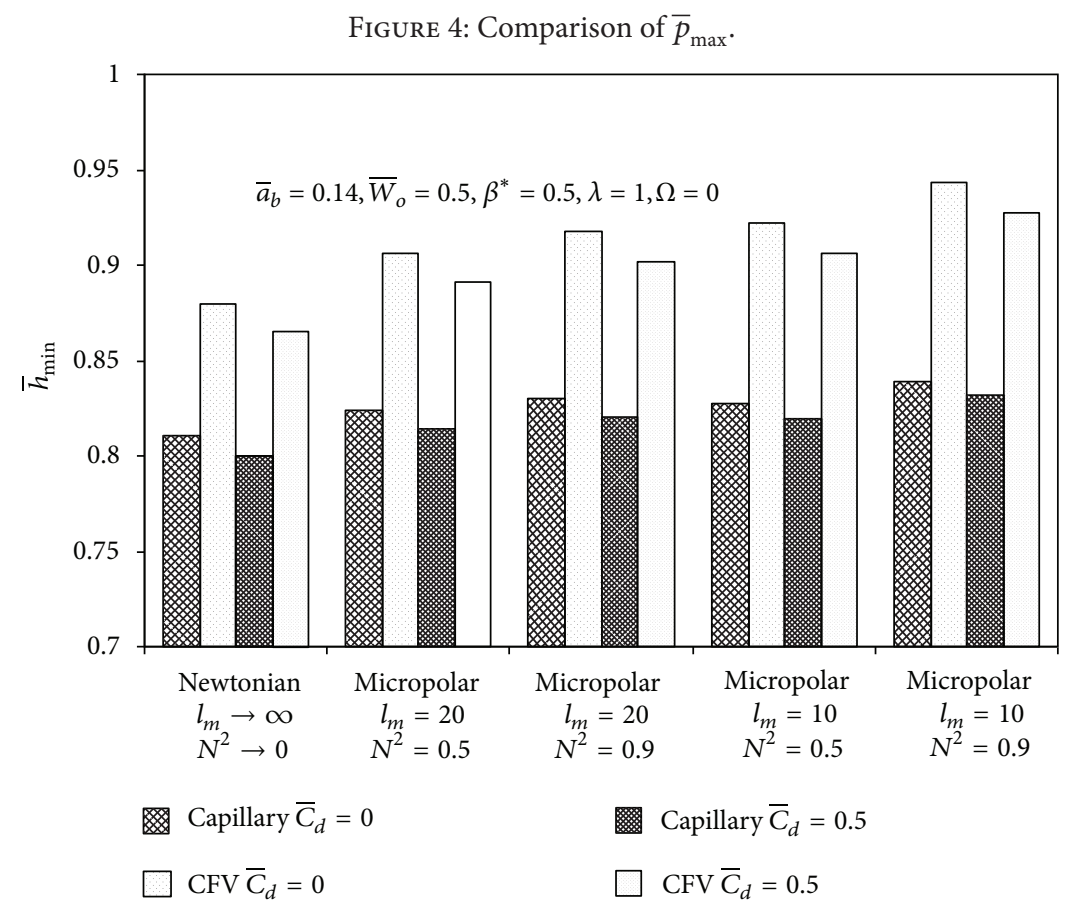

FIgURE 5: Comparison of $\bar{h}_{\min }$.

$$
\begin{aligned}
& \left(\left(\left.\bar{Q}\right|_{\text {CFV }}\right)_{\text {Rigid }}=\left(\left.\bar{Q}\right|_{\text {CFV }}\right)_{\text {Flexible }}\right)>\left(\left.\bar{Q}\right|_{\text {Capillary }}\right)_{\text {Flexible }} \\
& >\left(\left.\bar{Q}\right|_{\text {Capillary }}\right)_{\text {Rigid }}
\end{aligned}
$$

\section{for the micropolar lubricant;}

From Figure 7, it may be noted that the value of the direct fluid-film stiffness coefficient $\bar{S}_{X X}$ is larger for constant-flowvalve-compensated rigid and flexible bearing for all the values of the micropolar parameters of the lubricant. In general, the value of $\bar{S}_{X X}$ is seen to follow a definite pattern as follows:

$$
\begin{gathered}
\left(\left.\bar{S}_{X X}\right|_{\mathrm{CFV}}\right)_{\text {Rigid }}>\left(\left.\bar{S}_{X X}\right|_{\mathrm{CFV}}\right)_{\text {Flexible }}>\left(\left.\bar{S}_{X X}\right|_{\text {Capillary }}\right)_{\text {Rigid }} \\
>\left(\left.\bar{S}_{X X}\right|_{\text {Capillary }}\right)_{\text {Flexible }}
\end{gathered}
$$

for both the Newtonian and micropolar lubricants.

It may be observed from Figure 8 that the values of direct stiffness coefficient in vertical direction $\left(\bar{S}_{Z Z}\right)$ are more in the 


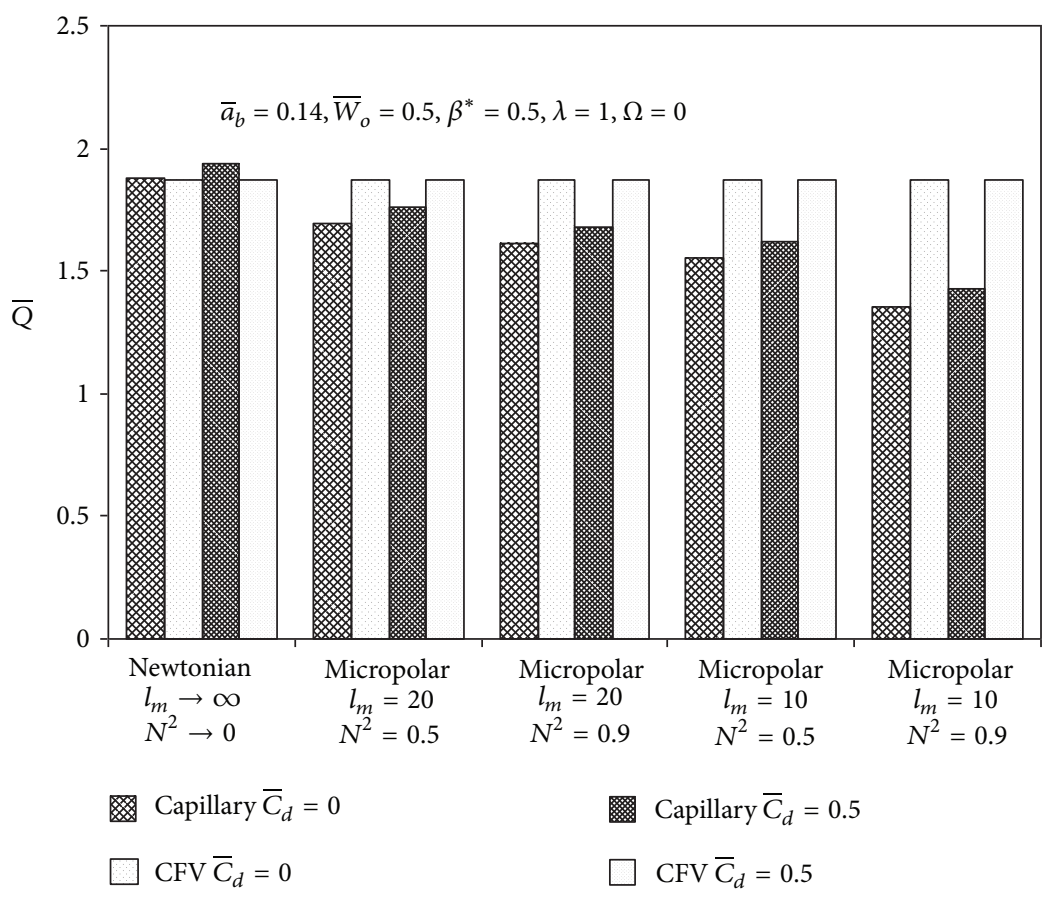

Figure 6: Comparison of $\bar{Q}$.

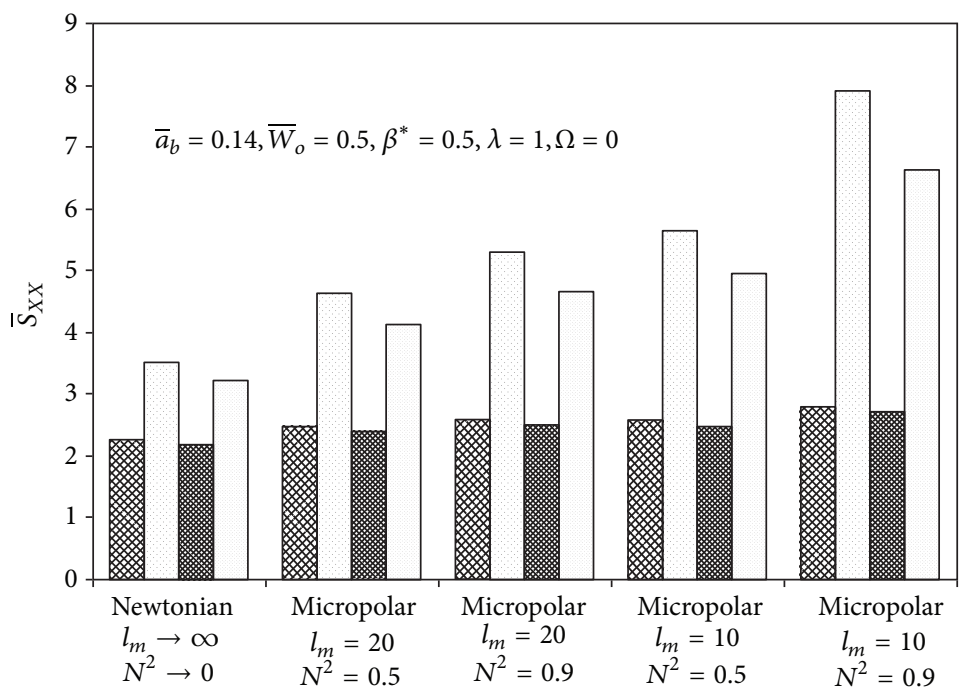
Capillary $\bar{C}_{d}=0$
Capillary $\bar{C}_{d}=0.5$
$\mathrm{CFV} \overline{\mathrm{C}}_{d}=0$
$\mathrm{CFV} \overline{\mathrm{C}}_{d}=0.5$

Figure 7: Comparison of $\bar{S}_{X X}$.

case of rigid bearing than that of the values of $\bar{S}_{Z Z}$ provided by corresponding flexible bearing irrespective of the type of compensating element used. It is further observed that for the same geometric and operating parameters, the value of $\bar{S}_{Z Z}$ is the largest for the constant-flow-valve-compensated bearings compared to the capillary-compensated bearings. For $\bar{S}_{Z Z}$, the following pattern is observed:

$$
\begin{aligned}
& \left(\left.\bar{S}_{Z Z}\right|_{\mathrm{CFV}}\right)_{\text {Rigid }}>\left(\left.\bar{S}_{Z Z}\right|_{\mathrm{CFV}}\right)_{\text {Flexible }}>\left(\left.\bar{S}_{Z Z}\right|_{\text {Capillary }}\right)_{\text {Rigid }} \\
& >\left(\left.\bar{S}_{Z Z}\right|_{\text {Capillary }}\right)_{\text {Flexible }}
\end{aligned}
$$

for both the Newtonian and micropolar lubricants. 


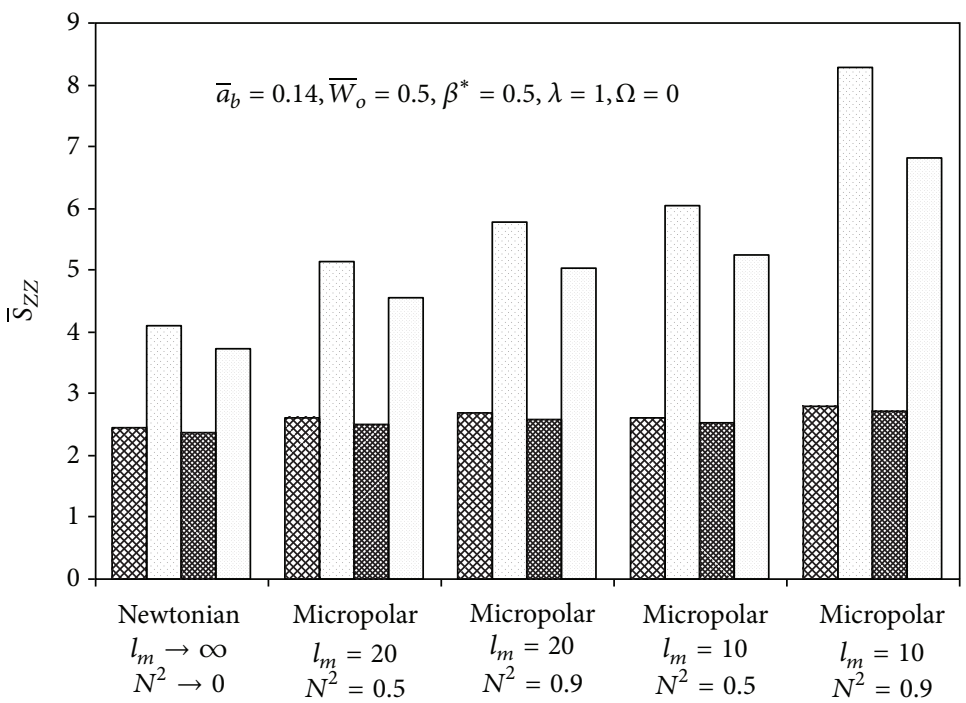
Capillary $\bar{C}_{d}=0$
Capillary $\bar{C}_{d}=0.5$
$\square \mathrm{CFV} \bar{C}_{d}=0$
$\mathrm{CFV} \bar{C}_{d}=0.5$

FIgURE 8: Comparison of $\bar{S}_{Z Z}$.

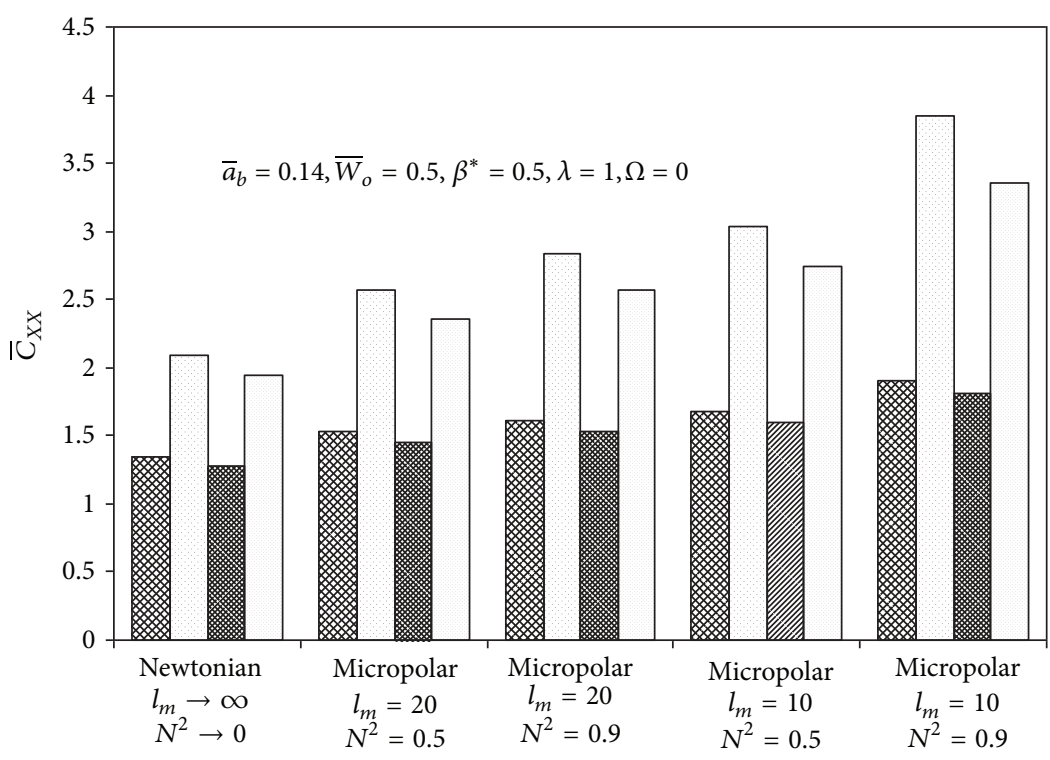
Capillary $\bar{C}_{d}=0$
Capillary $\bar{C}_{d}=0.5$
$\square \mathrm{CFV} \bar{C}_{d}=0$
$\square \mathrm{CFV} \bar{C}_{d}=0.5$

Figure 9: Comparison of $\bar{C}_{X X}$.

It can be observed from Figure 9 that the constantflow-valve-compensated rigid bearing provides the largest value of direct damping coefficient $\bar{C}_{X X}$ as compared to the capillary-compensated bearings, when the bearing is operating with the Newtonian or micropolar lubricant. The following pattern is observed for all the values of micropolar parameters $\left(N^{2}, l_{m}\right)$ of the lubricant:

$$
\begin{aligned}
& \left(\left.\bar{C}_{X X}\right|_{\text {CFV }}\right)_{\text {Rigid }}>\left(\left.\bar{C}_{X X}\right|_{\text {CFV }}\right)_{\text {Flexible }}>\left(\left.\bar{C}_{X X}\right|_{\text {Capillary }}\right)_{\text {Rigid }} \\
& >\left(\left.\bar{C}_{X X}\right|_{\text {Capillary }}\right)_{\text {Flexible }} .
\end{aligned}
$$

The values of direct damping coefficient in the direction of load $\left(\bar{C}_{Z Z}\right)$ show similar behavior as observed for the case 


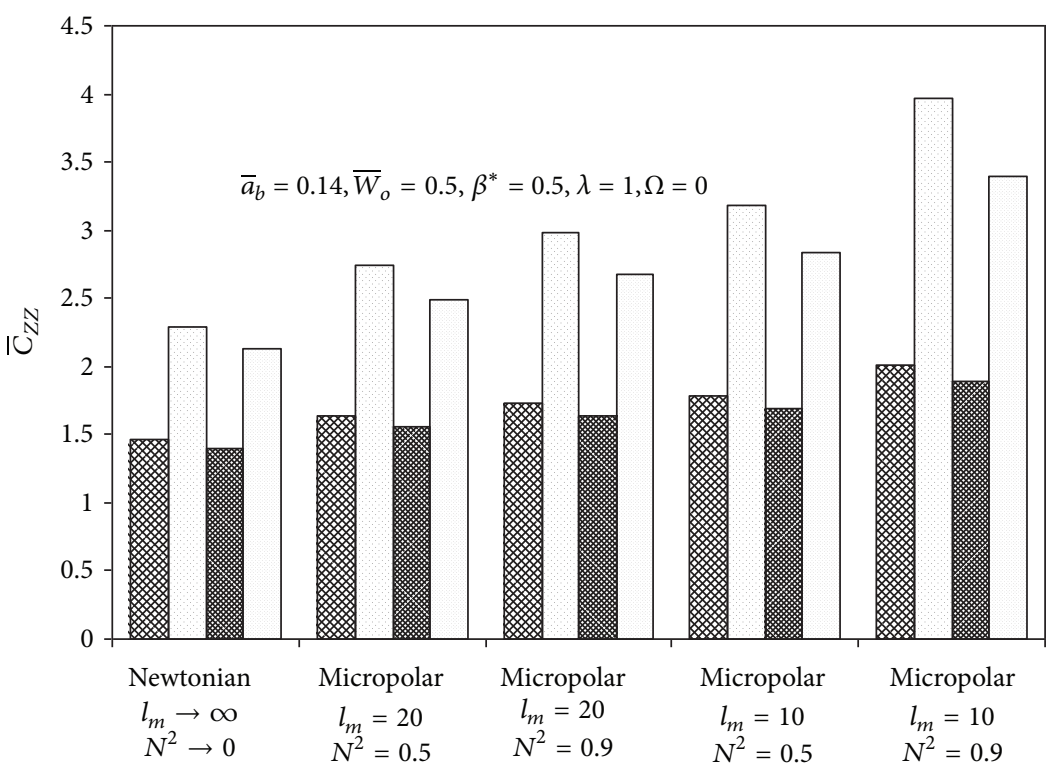
Capillary $\bar{C}_{d}=0$
Capillary $\bar{C}_{d}=0.5$
$\operatorname{CFV} \bar{C}_{d}=0$
$\square \mathrm{CFV} \bar{C}_{d}=0.5$

Figure 10: Comparison of $\bar{C}_{Z Z}$.

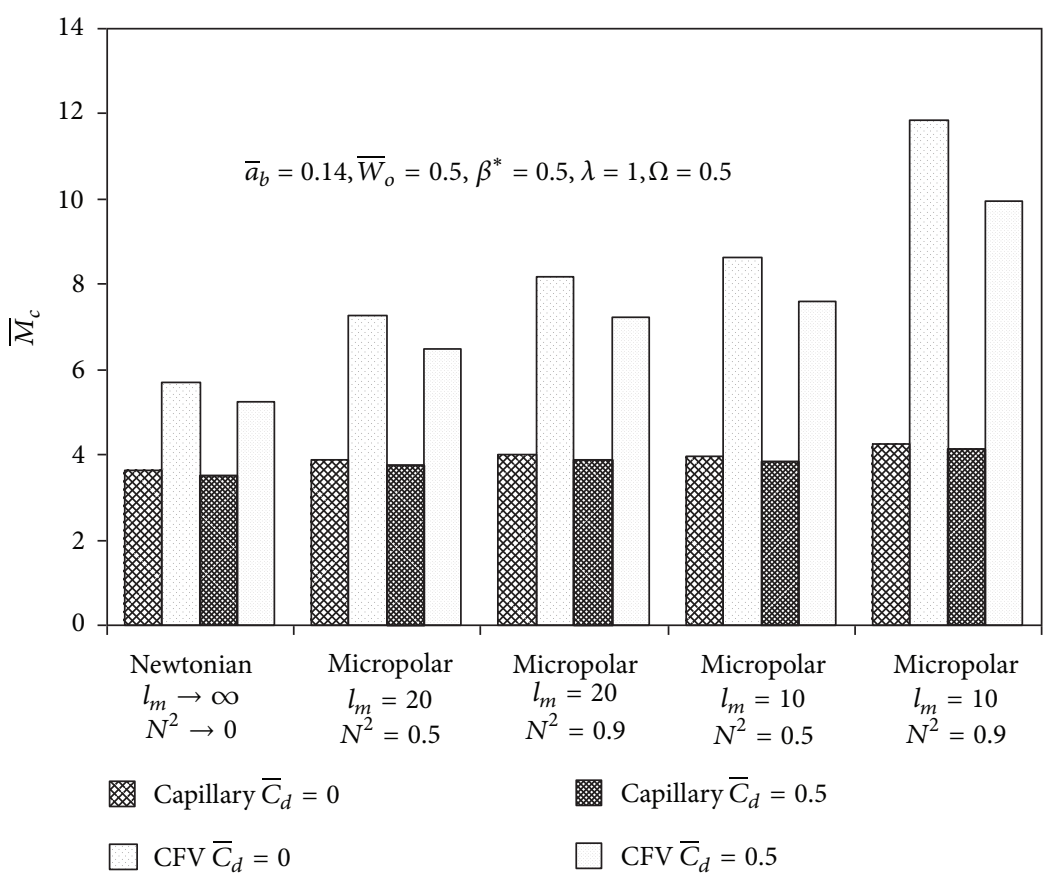

Figure 11: Comparison of $\bar{M}_{c}$.

of $\bar{C}_{X X}$ as shown in Figure 10 and is given as

$$
\begin{aligned}
& \left(\left.\bar{C}_{Z Z}\right|_{\mathrm{CFV}}\right)_{\text {Rigid }}>\left(\left.\bar{C}_{Z Z}\right|_{\mathrm{CFV}}\right)_{\text {Flexible }}>\left(\left.\bar{C}_{Z Z}\right|_{\text {Capillary }}\right)_{\text {Rigid }} \\
& >\left(\left.\bar{C}_{Z Z}\right|_{\text {Capillary }}\right)_{\text {Flexible }}
\end{aligned}
$$

for both the Newtonian and micropolar lubricants.
5.2. Comparison of Performance Characteristics in Hybrid Mode $(\Omega=0.5)$. In this section, the comparison between the performance characteristics of the multirecessed hydrostatic/hybrid journal bearings compensated with constant flow valve (CFV) and capillary restrictors has been presented at speed parameter $\Omega=0.5$.

It can be observed from Table 2 that the rigid bearing compensated with CFV gives more value of $\bar{p}_{\max }$ for all 


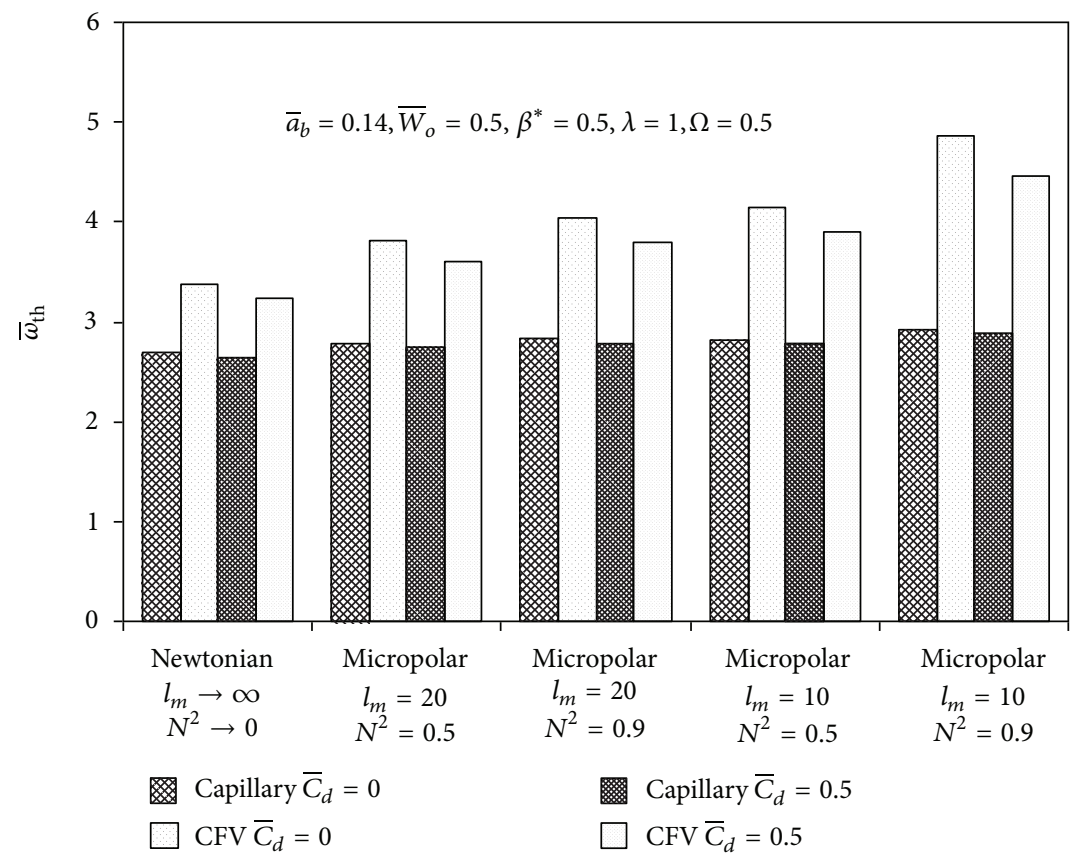

Figure 12: Comparison of $\bar{\omega}_{\text {th }}$.

the values of the micropolar parameters of the lubricant as compared to the capillary in hybrid mode of operation. The value of $\bar{p}_{\max }$ is seen to follow a definite pattern for hybrid mode of operation as given by

$$
\left.\bar{p}_{\text {max }}\right|_{\mathrm{CFV}}>\left.\bar{p}_{\text {max }}\right|_{\text {Capillary }}
$$

for the Newtonian and micropolar lubricants and rigid bearing

$$
\left.\bar{p}_{\max }\right|_{\text {Capillary }}>\left.\bar{p}_{\max }\right|_{\mathrm{CFV}}
$$

for the Newtonian lubricant and flexible bearing

$$
\left.\bar{p}_{\text {max }}\right|_{\mathrm{CFV}}>\left.\bar{p}_{\text {max }}\right|_{\text {Capillary }}
$$

for the micropolar lubricant and flexible bearing.

It is observed from Table 2 that for rigid as well as the flexible hybrid bearing, the constant-flow-valve-compensated bearing shows maximum values of minimum fluid-film thickness $\left(\bar{h}_{\text {min }}\right)$, while the capillary-compensated bearing shows the lower value of $\bar{h}_{\text {min }}$ for both the Newtonian and micropolar lubricants. The following general trend is observed for all the values of micropolar parameters of the lubricant:

$$
\begin{aligned}
& \left(\left.\bar{h}_{\text {min }}\right|_{\mathrm{CFV}}\right)_{\text {Rigid }}>\left(\left.\bar{h}_{\text {min }}\right|_{\mathrm{CFV}}\right)_{\text {Flexible }}>\left(\left.\bar{h}_{\text {min }}\right|_{\text {Capillary }}\right)_{\text {Rigid }} \\
& \quad>\left(\left.\bar{h}_{\text {min }}\right|_{\text {Capillary }}\right)_{\text {Flexible }} .
\end{aligned}
$$

The flow requirement $\bar{Q}$ of flexible bearing is found to be more as compared to rigid bearing for capillary restrictor for all the values of micropolar parameters. The following trends are observed:

$$
\begin{aligned}
& \left(\left.\bar{Q}\right|_{\text {Capillary }}\right)_{\text {Flexible }}>\left(\left.\bar{Q}\right|_{\text {Capillary }}\right)_{\text {Rigid }} \\
& >\left(\left(\left.\bar{Q}\right|_{\text {CFV }}\right)_{\text {Rigid }}=\left(\left.\bar{Q}\right|_{\text {CFV }}\right)_{\text {Flexible }}\right)
\end{aligned}
$$

for the Newtonian lubricants

$$
\begin{aligned}
& \left(\left(\left.\bar{Q}\right|_{\text {CFV }}\right)_{\text {Rigid }}=\left(\left.\bar{Q}\right|_{\text {CFV }}\right)_{\text {Flexible }}\right)>\left(\left.\bar{Q}\right|_{\text {Capillary }}\right)_{\text {Flexible }} \\
& >\left(\left.\bar{Q}\right|_{\text {Capillary }}\right)_{\text {Rigid }}
\end{aligned}
$$

for the micropolar lubricants.

For both CFV as well as capillary restrictors, the value of attitude angle $(\phi)$ is observed to increase with increase in bearing flexibility. For CFV-compensated rigid bearing, the value of $\phi$ decreases with increase in micropolar effect of lubricant as compared to the Newtonian lubricant, while, the opposite is true for capillary restrictor. The following trend is observed for all the values of micropolar parameters of the lubricant:

$$
\begin{aligned}
& \left(\left.\phi\right|_{\text {CFV }}\right)_{\text {Flexible }}>\left(\left.\phi\right|_{\text {Capillary }}\right)_{\text {Flexible }}>\left(\left.\phi\right|_{\text {Capillary }}\right)_{\text {Rigid }} \\
& >\left(\left.\phi\right|_{\text {CFV }}\right)_{\text {Rigid }} .
\end{aligned}
$$

From Table 3, it may be noted that the value of direct fluid-film stiffness coefficient $\bar{S}_{X X}$ is larger for constant-flowvalve-compensated rigid as well as flexible bearings for all the values of the micropolar parameters of the lubricant. In 
TABLE 2: Comparison of static performance characteristics.

\begin{tabular}{|c|c|c|c|c|c|c|c|c|}
\hline \multirow{3}{*}{ Static characteristics } & \multirow{3}{*}{$N^{2}$} & \multirow{3}{*}{$l_{m}$} & \multicolumn{6}{|c|}{ Performance comparison in Hybrid mode $(\Omega=0.5)$} \\
\hline & & & \multicolumn{3}{|c|}{ Rigid bearing $\left(\bar{C}_{d}=0.0\right)$} & \multicolumn{3}{|c|}{ Flexible bearing $\left(\bar{C}_{d}=0.5\right)$} \\
\hline & & & CFV & Capillary & \% Diff. & CFV & Capillary & $\%$ Diff. \\
\hline \multirow{5}{*}{$\bar{P}_{\max }$} & \multicolumn{2}{|c|}{ Newtonian } & 0.612692 & 0.60824 & 0.73 & 0.582657 & 0.591998 & -1.58 \\
\hline & 0.5 & 20 & 0.721793 & 0.656583 & 9.93 & 0.675257 & 0.637741 & 5.88 \\
\hline & 0.9 & 20 & 0.780406 & 0.678793 & 14.97 & 0.723369 & 0.658657 & 9.82 \\
\hline & 0.5 & 10 & 0.828036 & 0.694896 & 19.16 & 0.76353 & 0.674496 & 13.2 \\
\hline & 0.9 & 10 & 1.0149 & 0.748414 & 35.61 & 0.908027 & 0.725063 & 25.23 \\
\hline \multirow{5}{*}{$\bar{h}_{\min }$} & \multicolumn{2}{|c|}{ Newtonian } & 0.868863 & 0.794968 & 9.3 & 0.852074 & 0.78211 & 8.95 \\
\hline & 0.5 & 20 & 0.897412 & 0.81159 & 10.57 & 0.880075 & 0.799163 & 10.13 \\
\hline & 0.9 & 20 & 0.909153 & 0.819027 & 11 & 0.891475 & 0.806767 & 10.5 \\
\hline & 0.5 & 10 & 0.914455 & 0.818917 & 11.67 & 0.89673 & 0.807027 & 11.12 \\
\hline & 0.9 & 10 & 0.937497 & 0.833631 & 12.46 & 0.918875 & 0.82224 & 11.75 \\
\hline \multirow{5}{*}{$\bar{Q}$} & \multicolumn{2}{|c|}{ Newtonian } & 1.87 & 1.87867 & -0.46 & 1.87 & 1.93459 & -3.34 \\
\hline & 0.5 & 20 & 1.87 & 1.69388 & 10.4 & 1.87 & 1.75831 & 6.354 \\
\hline & 0.9 & 20 & 1.87 & 1.60927 & 16.2 & 1.87 & 1.67792 & 11.45 \\
\hline & 0.5 & 10 & 1.87 & 1.54748 & 20.84 & 1.87 & 1.61689 & 15.65 \\
\hline & 0.9 & 10 & 1.87 & 1.34413 & 39.12 & 1.87 & 1.42303 & 31.41 \\
\hline \multirow{5}{*}{$\phi$} & \multicolumn{2}{|c|}{ Newtonian } & 28.7463 & 28.6634 & 0.29 & 31.8554 & 30.4162 & 4.73 \\
\hline & 0.5 & 20 & 27.0985 & 29.6314 & -8.55 & 32.1468 & 31.6025 & 1.72 \\
\hline & 0.9 & 20 & 26.1998 & 29.9903 & -12.64 & 32.3376 & 32.0758 & 0.82 \\
\hline & 0.5 & 10 & 26.3315 & 31.1599 & -15.5 & 33.0915 & 33.1452 & -0.16 \\
\hline & 0.9 & 10 & 24.073 & 32.3095 & -25.49 & 34.5794 & 34.4733 & 0.31 \\
\hline
\end{tabular}

general, the value of $\bar{S}_{X X}$ is seen to follow a definite pattern given as

$$
\begin{aligned}
& \left(\left.\bar{S}_{X X}\right|_{\mathrm{CFV}}\right)_{\text {Rigid }}>\left(\left.\bar{S}_{X X}\right|_{\mathrm{CFV}}\right)_{\text {Flexible }}>\left(\left.\bar{S}_{X X}\right|_{\text {Capillary }}\right)_{\text {Rigid }} \\
& >\left(\left.\bar{S}_{X X}\right|_{\text {Capillary }}\right)_{\text {Flexible }}
\end{aligned}
$$

for both the Newtonian and micropolar lubricants.

It is noticed that the values of cross-coupled coefficients $\left(\bar{S}_{X Z},-\bar{S}_{Z X}\right)$ are more for rigid bearing $\left(\bar{C}_{d}=0.0\right)$ as compared with flexible bearing $\left(\bar{C}_{d}=0.5\right)$. For rigid and flexible bearings, constant-flow-valve-compensated bearing shows the largest value of $\bar{S}_{X Z}$ for the Newtonian and micropolar lubricants. The following trend is observed for all the values of the micropolar parameters of the lubricant:

$$
\begin{aligned}
& \left(\left.\bar{S}_{X Z}\right|_{\mathrm{CFV}}\right)_{\text {Rigid }}>\left(\left.\bar{S}_{X Z}\right|_{\mathrm{CFV}}\right)_{\text {Flexible }}>\left(\left.\bar{S}_{X Z}\right|_{\text {Capillary }}\right)_{\text {Rigid }} \\
& >\left(\left.\bar{S}_{X Z}\right|_{\text {Capillary }}\right)_{\text {Flexible }} \cdot
\end{aligned}
$$

The similar trend has been observed for cross-coupled coefficient $\left(-\bar{S}_{Z X}\right)$ except that the values of cross-coupled coefficient $\bar{S}_{Z X}$ are negative.

It may be observed from Table 3 that the values of direct stiffness coefficient in vertical direction $\left(\bar{S}_{Z Z}\right)$ are more in the case of rigid bearing than that of the values of $\bar{S}_{Z Z}$ provided by corresponding flexible bearing irrespective of the type of compensating element used. It is further observed that for the same geometric and operating parameters, the value of $\bar{S}_{Z Z}$ is the largest for constant-flow-valve-compensated bearings compared to the capillary-compensated bearings. For $\bar{S}_{Z Z}$, the following pattern is observed:

$$
\begin{aligned}
& \left(\left.\bar{S}_{Z Z}\right|_{\mathrm{CFV}}\right)_{\text {Rigid }}>\left(\left.\bar{S}_{Z Z}\right|_{\mathrm{CFV}}\right)_{\text {Flexible }}>\left(\left.\bar{S}_{Z Z}\right|_{\text {Capillary }}\right)_{\text {Rigid }} \\
& \quad>\left(\left.\bar{S}_{Z Z}\right|_{\text {Capillary }}\right)_{\text {Flexible }}
\end{aligned}
$$

for both the Newtonian and micropolar lubricants.

It can be observed again from Table 3 that constant-flowvalve-compensated rigid bearing provides the largest value of direct damping coefficient $\bar{C}_{X X}$ as compared to capillarycompensated bearings, when the bearing is operating with the Newtonian or micropolar lubricant. The following pattern is observed for all the values of micropolar parameters $\left(N^{2}, l_{m}\right)$ of the lubricant:

$$
\begin{aligned}
& \left(\left.\bar{C}_{X X}\right|_{C F V}\right)_{\text {Rigid }}>\left(\left.\bar{C}_{X X}\right|_{\text {CFV }}\right)_{\text {Flexible }}>\left(\left.\bar{C}_{X X}\right|_{\text {Capillary }}\right)_{\text {Rigid }} \\
& >\left(\left.\bar{C}_{X X}\right|_{\text {Capillary }}\right)_{\text {Flexible }} \cdot
\end{aligned}
$$


TABLE 3: Comparison of stiffness and damping coefficients.

\begin{tabular}{|c|c|c|c|c|c|c|c|c|}
\hline \multirow{3}{*}{ Dynamic characteristics } & \multirow{3}{*}{$N^{2}$} & \multirow{3}{*}{$l_{m}$} & \multicolumn{6}{|c|}{ Performance comparison in hybrid mode $(\Omega=0.5)$} \\
\hline & & & \multicolumn{3}{|c|}{ Rigid bearing $\left(\bar{C}_{d}=0.0\right)$} & \multicolumn{3}{|c|}{ Flexible bearing $\left(\bar{C}_{d}=0.5\right)$} \\
\hline & & & CFV & Capillary & $\%$ Diff & CFV & Capillary & $\%$ Diff \\
\hline \multirow{5}{*}{$\bar{S}_{X X}$} & \multicolumn{2}{|c|}{ Newtonian } & 3.54301 & 2.27482 & 55.75 & 3.23627 & 2.18368 & 48.20 \\
\hline & 0.5 & 20 & 4.65422 & 2.48465 & 87.32 & 4.1514 & 2.3875 & 73.88 \\
\hline & 0.9 & 20 & 5.31347 & 2.58922 & 105.22 & 4.6763 & 2.48892 & 87.88 \\
\hline & 0.5 & 10 & 5.64979 & 2.56437 & 120.32 & 4.94724 & 2.47348 & 100.01 \\
\hline & 0.9 & 10 & 7.9128 & 2.78698 & 183.92 & 6.6325 & 2.69533 & 146.07 \\
\hline \multirow{5}{*}{$\bar{S}_{X Z}=-\bar{S}_{Z X}$} & \multicolumn{2}{|c|}{ Newtonian } & 1.83132 & 1.16368 & 57.37 & 1.71806 & 1.11428 & 54.19 \\
\hline & 0.5 & 20 & 2.21482 & 1.30984 & 69.09 & 2.04087 & 1.24951 & 63.33 \\
\hline & 0.9 & 20 & 2.42169 & 1.38037 & 75.44 & 2.20832 & 1.31431 & 68.02 \\
\hline & 0.5 & 10 & 2.58848 & 1.4298 & 81.04 & 2.34717 & 1.36178 & 72.36 \\
\hline & 0.9 & 10 & 3.24954 & 1.61102 & 101.71 & 2.85026 & 1.52843 & 86.48 \\
\hline \multirow{5}{*}{$\bar{S}_{Z Z}$} & \multicolumn{2}{|c|}{ Newtonian } & 4.00934 & 2.463 & 62.78 & 3.65601 & 2.37157 & 54.16 \\
\hline & 0.5 & 20 & 5.07072 & 2.62838 & 92.92 & 4.49692 & 2.53378 & 77.48 \\
\hline & 0.9 & 20 & 5.71536 & 2.71743 & 110.32 & 4.98722 & 2.62107 & 90.27 \\
\hline & 0.5 & 10 & 6.00467 & 2.6614 & 125.62 & 5.20757 & 2.57873 & 101.94 \\
\hline & 0.9 & 10 & 8.2406 & 2.85221 & 188.92 & 6.78391 & 2.7746 & 144.50 \\
\hline \multirow{5}{*}{$\bar{C}_{X X}$} & \multicolumn{2}{|c|}{ Newtonian } & 2.13626 & 1.37351 & 55.53 & 1.99885 & 1.31266 & 52.27 \\
\hline & 0.5 & 20 & 2.60824 & 1.55894 & 67.31 & 2.39473 & 1.4845 & 61.32 \\
\hline & 0.9 & 20 & 2.86087 & 1.64737 & 73.66 & 2.59901 & 1.56582 & 65.98 \\
\hline & 0.5 & 10 & 3.06806 & 1.71482 & 78.91 & 2.77192 & 1.63065 & 69.99 \\
\hline & 0.9 & 10 & 3.87129 & 1.94261 & 99.28 & 3.3804 & 1.84013 & 83.70 \\
\hline \multirow{5}{*}{$\bar{C}_{X Z} \approx \bar{C}_{Z X}$} & \multicolumn{2}{|c|}{ Newtonian } & 0.011232 & 0.007723 & 45.44 & 0.012013 & 0.008362 & 43.66 \\
\hline & 0.5 & 20 & 0.009318 & 0.006665 & 39.81 & 0.011956 & 0.00764 & 56.49 \\
\hline & 0.9 & 20 & 0.008675 & 0.006294 & 37.83 & 0.01212 & 0.007447 & 62.75 \\
\hline & 0.5 & 10 & 0.00778 & 0.00524 & 48.47 & 0.011899 & 0.00657 & 81.11 \\
\hline & 0.9 & 10 & 0.006611 & 0.003998 & 65.36 & 0.014291 & 0.005943 & 140.47 \\
\hline \multirow{5}{*}{$\bar{C}_{Z Z}$} & \multicolumn{2}{|c|}{ Newtonian } & 2.2232 & 1.42599 & 55.91 & 2.06051 & 1.35568 & 51.99 \\
\hline & 0.5 & 20 & 2.68794 & 1.60386 & 67.59 & 2.43585 & 1.51768 & 60.50 \\
\hline & 0.9 & 20 & 2.93783 & 1.68958 & 73.88 & 2.62917 & 1.59509 & 64.83 \\
\hline & 0.5 & 10 & 3.13877 & 1.75164 & 79.19 & 2.78981 & 1.65411 & 68.66 \\
\hline & 0.9 & 10 & 3.93504 & 1.97308 & 99.44 & 3.35903 & 1.85416 & 81.16 \\
\hline
\end{tabular}

The values of direct damping coefficient in the direction of load $\left(\bar{C}_{Z Z}\right)$ show similar behavior as observed for the case of $\bar{C}_{X X}$ and are given as

$$
\begin{aligned}
& \left(\left.\bar{C}_{Z Z}\right|_{C F V}\right)_{\text {Rigid }}>\left(\left.\bar{C}_{Z Z}\right|_{C F V}\right)_{\text {Flexible }}>\left(\left.\bar{C}_{Z Z}\right|_{\text {Capillary }}\right)_{\text {Rigid }} \\
& >\left(\left.\bar{C}_{Z Z}\right|_{\text {Capillary }}\right)_{\text {Flexible }}
\end{aligned}
$$

for the both Newtonian and micropolar lubricants.

The values of the cross-coupled coefficient $\left(\bar{C}_{X Z} \approx \bar{C}_{Z X}\right)$ in Table 3 indicate that these coefficients are smaller for capillary-compensated bearing as compared to the CFV for all the values of the micropolar parameters of the lubricant. For cross-coupled damping coefficients, the following patterns are obtained for rigid and flexible bearings:

$$
\begin{aligned}
& \left(\left.\bar{C}_{X Z}\right|_{\mathrm{CFV}}\right)_{\text {Flexible }}>\left(\left.\bar{C}_{X Z}\right|_{\mathrm{CFV}}\right)_{\text {Rigid }}>\left(\left.\bar{C}_{X Z}\right|_{\text {Capillary }}\right)_{\text {Flexible }} \\
& >\left(\left.\bar{C}_{X Z}\right|_{\text {Capillary }}\right)_{\text {Rigid }}
\end{aligned}
$$

for both the micropolar and Newtonian lubricants.

The bearing stability margin in terms of critical mass $\left(\bar{M}_{c}\right)$ and threshold speed $\left(\bar{\omega}_{\text {th }}\right)$ computed for four-pocketcompensated bearings is presented in Figures 11 and 12 for different values of the micropolar parameters. The comparative study of the bearing shows that for all the values of micropolar parameters $\left(N^{2}, l_{m}\right)$ of the lubricant, the constantflow-valve-compensated bearing provides the largest value of stability margin for both rigid as well as flexible bearings. It is clear from Figures 11 and 12 that the stability margin of compensated bearing of flexible bearing increases with increase in the micropolar effect of the lubricant. The following trend 
is observed for the entire stability margin of the bearing for both the Newtonian and micropolar lubricants:

$$
\begin{gathered}
\left(\left.\bar{M}_{c}\right|_{\text {CFV }}\right)_{\text {Rigid }}>\left(\left.\bar{M}_{c}\right|_{\text {CFV }}\right)_{\text {Flexible }}>\left(\left.\bar{M}_{c}\right|_{\text {Capillary }}\right)_{\text {Rigid }} \\
>\left(\left.\bar{M}_{c}\right|_{\text {Capillary }}\right)_{\text {Flexible }}, \\
\left(\left.\bar{\omega}_{\text {th }}\right|_{\text {CFV }}\right)_{\text {Rigid }}>\left(\left.\bar{\omega}_{\text {th }}\right|_{\text {CFV }}\right)_{\text {Flexible }}>\left(\left.\bar{\omega}_{\text {th }}\right|_{\text {Capillary }}\right)_{\text {Rigid }} \\
>\left(\left.\bar{\omega}_{\text {th }}\right|_{\text {Capillary }}\right)_{\text {Flexible }} .
\end{gathered}
$$

\section{Conclusion}

The comparison between the performance characteristics of the multirecessed hydrostatic/hybrid journal bearings compensated with constant flow valve and capillary restrictors, taking bearing flexibility and micropolar parameters of the lubricant into consideration, has been presented in this paper. This would help the designer to select a suitable compensating device for a bearing in conjunction with bearing flexibility to obtain the improved performance with micropolar lubricant. In general, it has been found that at various values of the micropolar parameters of the lubricant, a constant-flowvalve-compensated multirecessed hydrostatic journal bearing gives superior performance as compared to the capillary, from the point of view of minimum fluid-film thickness and stability parameters.

\section{Nomenclature}

\section{Dimensional Parameters}

$\begin{array}{ll}a_{b}: & \text { Land width }(\mathrm{m}) \\ c: & \text { Radial clearance }(\mathrm{m}) \\ D: & \text { Journal diameter }(\mathrm{m}) \\ E_{b}: & \text { Modulus of elasticity }\left(\mathrm{N} / \mathrm{m}^{-2}\right) \\ F: & \text { Fluid-film reaction }(\mathrm{N}) \\ h: & \text { Fluid-film thickness }(\mathrm{m}) \\ l: & \text { Characteristic length }(\mathrm{m}) \\ L: & \text { Bearing length }(\mathrm{m}) \\ p: & \text { Pressure }\left(\mathrm{N} \cdot \mathrm{m}^{-2}\right) \\ p_{s}: & \text { Supply pressure }\left(\mathrm{N} \cdot \mathrm{m}^{-2}\right) \\ Q: & \text { Bearing flow }\left(\mathrm{m}^{3} \cdot \mathrm{s}^{-1}\right) \\ r: & \text { Radial coordinate } \\ R_{J}: & \text { Journal radius }(\mathrm{m}) \\ t: & \text { Time }(\mathrm{s}) \\ t_{h}: & \text { Shell thickness } \\ u, v, w: & x, y \text { and } z \text { velocity components }\left(\mathrm{m} \cdot \mathrm{s}^{-1}\right) \\ W_{0}: & \text { External load }(\mathrm{N}) \\ X_{J}, Z_{J}: & \text { Journal center coordinates } \\ x, y: & \text { Circumferential and axial coordinates } \\ z: & \text { (m) }\end{array}$

$\mu: \quad$ Dynamic viscosity $(\mathrm{Pa} \cdot \mathrm{s})$

$v$ : Poisson's ratio

$\omega_{\text {I }}$ : Journal speed (rev per sec)

$\theta$ : Angle of interrecess land width (Figure 1(b)).

\section{Nondimensional Parameters}

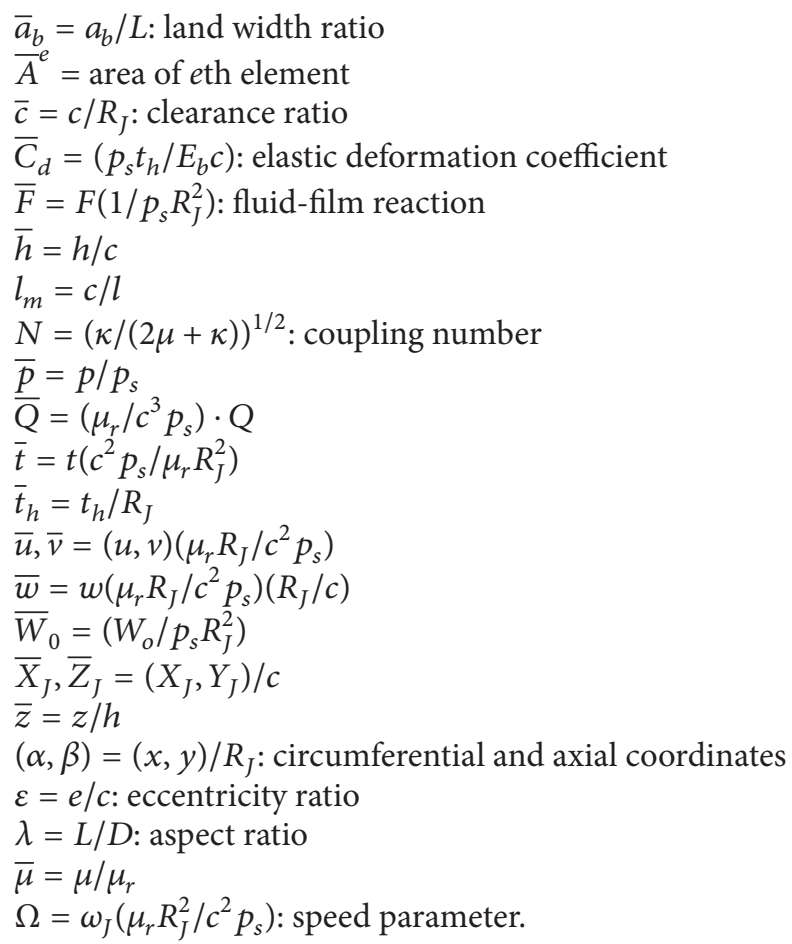

\section{Subscripts}
$b$ : Bearing
c: Pocket
J: Journal
$r$ : Reference value
$R$ : Restrictor
$s$ : Supply condition.

Matrices and Vectors

$\begin{array}{ll}N_{i}, N_{j}: & \text { Shape function matrices } \\ \{\bar{p}\}: & \text { Pressure vector } \\ \{\bar{Q}\}: & \text { Flow vector } \\ \left\{\bar{R}_{x J}\right\},\left\{\bar{R}_{z J}\right\}: & \text { Vectors due to journal velocity } \\ \left\{\bar{R}_{H}\right\}: & \text { Column vector (hydrodynamic term) } \\ {[M]:} & \text { Journal mass matrix }\end{array}$

\section{Abbreviations}

EHS: Elastohydrostatic

MEHS: Micropolar elastohydrostatic

MHS: Micropolar hydrostatic

NHS: Newtonian hydrostatic

RHS: Right-hand side. 


\section{References}

[1] R. Bassani and B. Piccigallo, Hydrostatic Lubrication, Tribology Series, vol. 22, Elsevier, New York, NY, USA, 1992.

[2] R. Sinhasan, S. C. Sharma, and S. C. Jain, "Performance characteristics of an externally pressurized capillary-compensated flexible journal bearing," Tribology International, vol. 22, no. 4, pp. 283-293, 1989.

[3] R. Sinhasan, S. C. Sharma, and S. C. Jain, "Performance characteristics of a constant flow valve compensated multirecess flexible hydrostatic journal bearing," Wear, vol. 134, no. 2, pp. 335-356, 1989.

[4] R. Sinhasan, S. C. Sharma, and S. C. Jain, "Performance characteristics of externally pressurized orifice compensated flexible journal bearing," Tribology Transactions, vol. 34, no. 3, pp. 465471, 1991.

[5] S. C. Sharma, R. Sinhasan, and S. C. Jain, "Performance characteristics of multirecess hydrostatic/hybrid flexible journal bearing with membrane type variable-flow restrictor as compensating elements," Wear, vol. 152, no. 2, pp. 279-300, 1992.

[6] S. C. Sharma, V. Kumar, S. C. Jain, R. Sinhasan, and M. Subramanian, "Study of slot-entry hydrostatic/hybrid journal bearing using the finite element method," Tribology International, vol. 32, no. 4, pp. 185-196, 1999.

[7] J. Prakash and P. Sinha, "Lubrication theory of micropolar fluids and its application to a journal bearing," International Journal of Engineering Science, vol. 13, pp. 217-232, 1975.

[8] J. Prakash and P. Sinha, "A study of squeezing flow in micropolar fluid lubricated journal bearings," Wear, vol. 38, no. 1, pp. 17-28, 1976.

[9] C. Singh and P. Sinha, "The three-dimensional Reynolds equation for micropolar fluid-lubricated bearings," Wear, vol. 76, no. 2, pp. 199-209, 1966.

[10] M. M. Khonsari and D. E. Brewe, "On the performance of finite journal bearings lubricated with micropolar fluids," Tribology Transactions, vol. 32, no. 2, pp. 155-160, 1989.

[11] S. Das, S. K. Guha, and A. K. Chattopadhyay, "On the conical whirl instability of hydrodynamic journal bearings lubricated with micropolar fluids," Proceedings of the Institution of Mechanical Engineers J, vol. 215, no. 5, pp. 431-439, 2001.

[12] S. Das, S. K. Guha, and A. K. Chattopadhyay, "On the steadystate performance of misaligned hydrodynamic journal bearings lubricated with micropolar fluids," Tribology International, vol. 35, no. 4, pp. 201-210, 2002.

[13] X. L. Wang and K. Q. Zhu, "A study of the lubricating effectiveness of micropolar fluids in a dynamically loaded journal bearing (T1516)," Tribology International, vol. 37, no. 6, pp. 481490, 2004.

[14] X. L. Wang and K. Q. Zhu, "Numerical analysis of journal bearings lubricated with micropolar fluids including thermal and cavitating effects," Tribology International, vol. 39, no. 3, pp. 227-237, 2006.

[15] S. Verma, V. Kumar, and K. D. Gupta, "Analysis of multirecess hydrostatic journal bearing operating with micropolar lubricant," Journal of Tribology, vol. 131, no. 2, Article ID 021103, 9 pages, 2009.

[16] S. Verma, K. D. Gupta, and V. Kumar, "Analysis of capillary compensated hole-entry hydrostatic/hybrid journal bearing operating with micropolar lubricant," in IUTAM Symposium on Emerging Trends in Rotor Dynamics, vol. 25 of IUTAM Springer Book Series, pp. 241-252, Springer, New York, NY, USA, 2011.
[17] E. R. Nicodemus and S. C. Sharma, "Influence of wear on the performance of multirecess hydrostatic journal bearing operating with micropolar lubricant," Journal of Tribology, vol. 132, no. 2, Article ID 021703, 11 pages, 2010.

[18] E. R. Nicodemus and S. C. Sharma, "Orifice compensated multirecess hydrostatic/hybrid journal bearing system of various geometric shapes of recess operating with micropolar lubricant," Tribology International, vol. 44, no. 3, pp. 284-296, 2011.

[19] S. Verma, V. K. Jadon, and K. D. Gupta, "Analysis of capillary compensated hydrostaticjournal bearing operating with micropolar lubricant," Industrial Lubrication and Tribology, vol. 63, no. 3, pp. 192-202, 2011.

[20] H. C. Garg, V. Kumar, and H. B. Sharda, "A comparative thermal analysis of slot-entry and hole-entry hybrid journal bearings lubricated with non-Newtonian lubricant," Journal of Tribology, vol. 132, no. 4, Article ID 041701, 11 pages, 2010.

[21] P. Khatak and H. C. Garg, "Influence of micropolar lubricant on bearings performance: a review," Proceedings of the Institution of Mechanical Engineers J, vol. 226, no. 9, pp. 775-784, 2012.

[22] E. R. Nicodemus and S. C. Sharma, "Performance characteristics of micropolar lubricated membrane-compensated worn hybrid journal bearings," Tribology Transactions, vol. 55, no. 1, pp. 59-70, 2012.

[23] S. Verma, V. Kumar, and K. D. Gupta, "Performance analysis of flexible multirecess hydrostatic journal bearing operating with micropolar lubricant," Lubrication Science, vol. 24, no. 6, pp. 273-292, 2012.

[24] S. C. Sharma and A. K. Rajput, "Effect of geometric imperfections of journal on the performance of micropolar lubricated 4-pocket hybrid journal bearing," Tribology International, vol. 60, pp. 156-168, 2013. 

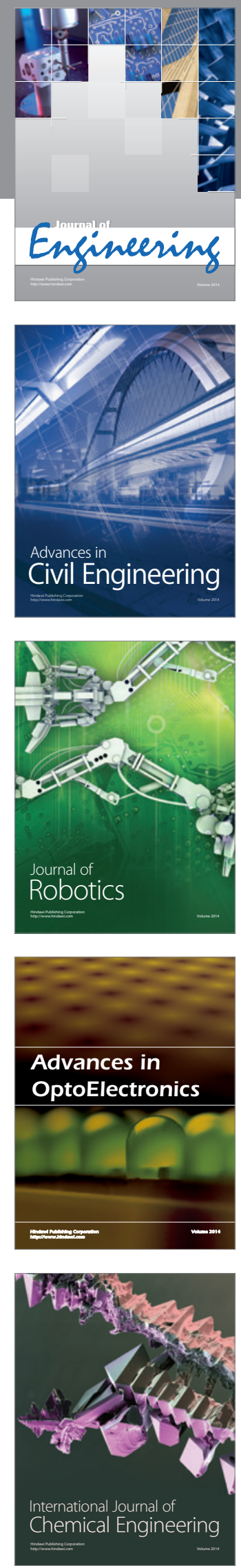

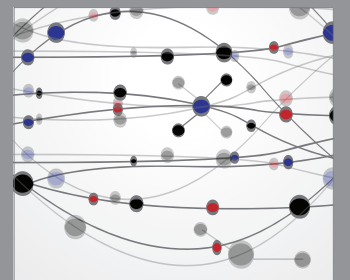

The Scientific World Journal
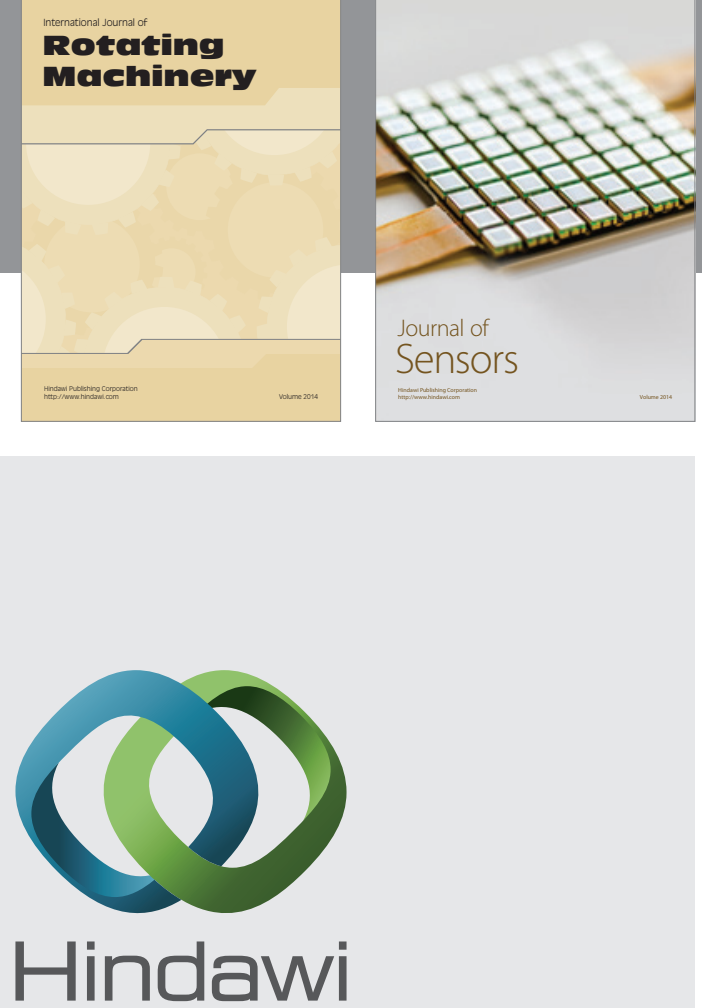

Submit your manuscripts at http://www.hindawi.com
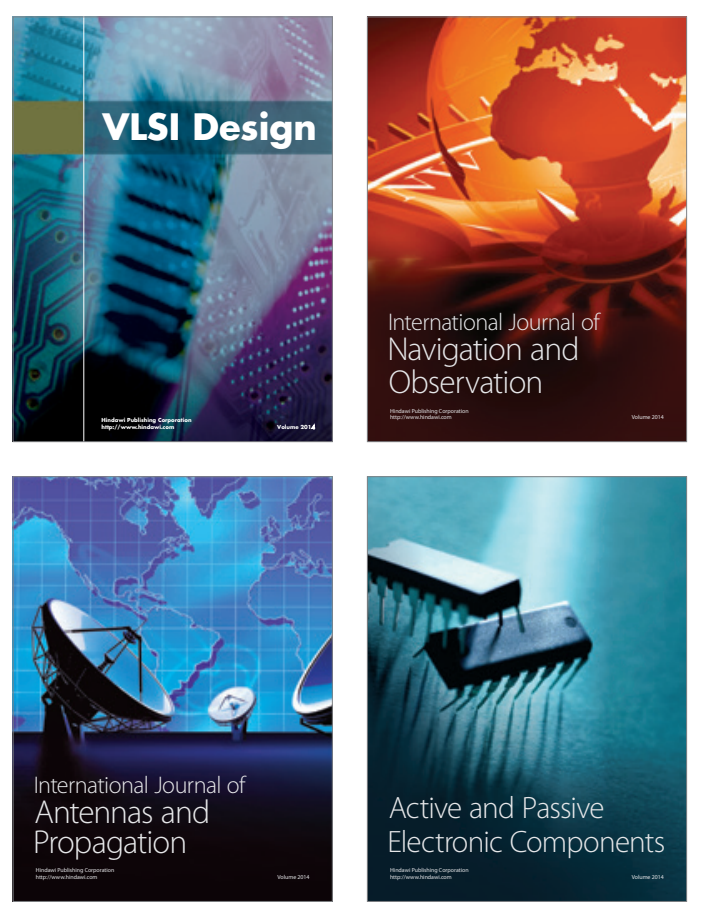
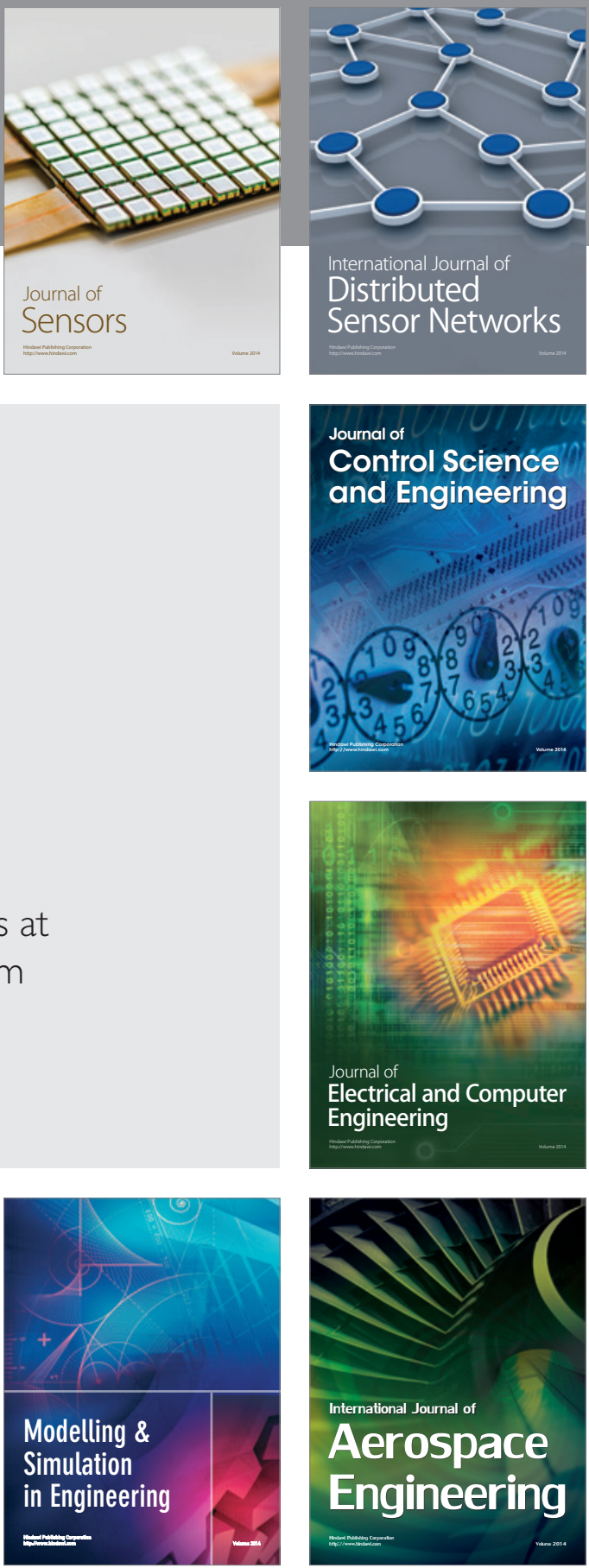

Journal of

Control Science

and Engineering
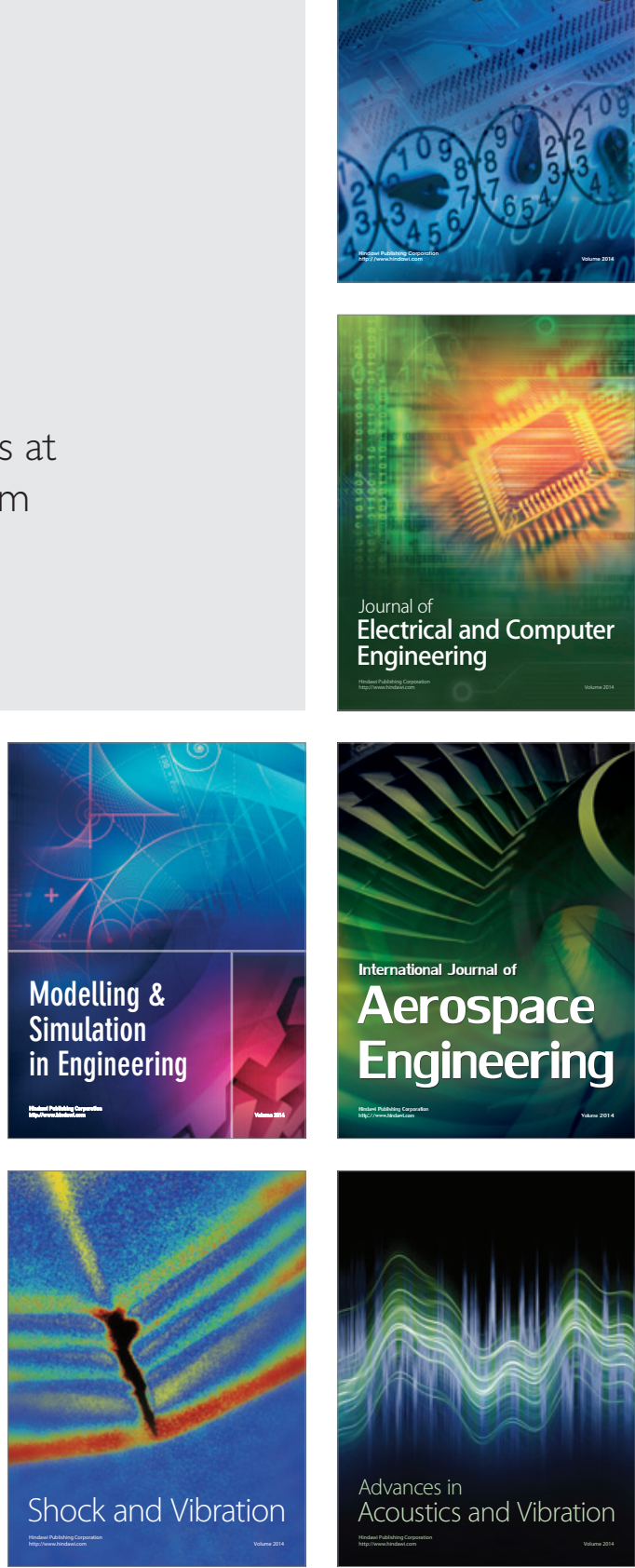